\title{
Policy Ideology in European Mass Publics, 1981-2016
}

\author{
DEVIN CAUGHEY Massachusetts Institute of Technology \\ TOM O'GRADY University College London

\section{CHRISTOPHER WARSHAW George Washington University}

\begin{abstract}
$T$ sing new scaling methods and a comprehensive public opinion dataset, we develop the first surveybased time-series-cross-sectional measures of policy ideology in European mass publics. Our dataset covers 27 countries and 36 years and contains nearly 2.7 million survey responses to 109 unique issue questions. Estimating an ordinal group-level IRT model in each of four issue domains, we obtain biennial estimates of the absolute economic conservatism, relative economic conservatism, social conservatism, and immigration conservatism of men and women in three age categories in each country. Aggregating the group-level estimates yields estimates of the average conservatism in national publics in each biennium between 1981-82 and 2015-16. The four measures exhibit contrasting cross-sectional cleavages and distinct temporal dynamics, illustrating the multidimensionality of mass ideology in Europe. Subjecting our measures to a series of validation tests, we show that the constructs they measure are distinct and substantively important and that they perform as well as or better than one-dimensional proxies for mass conservatism (left-right self-placement and median voter scores). We foresee many uses for these scores by scholars of public opinion, electoral behavior, representation, and policy feedback.
\end{abstract}

\section{INTRODUCTION}

$\mathbf{H}$ ow do citizens' policy preferences vary across countries? How do they differ across issue domains? How have they changed over time? What are the sources of these ideological differences? How do mass preferences affect electoral and policy outcomes? Which political institutions inhibit or enhance government responsiveness to citizens' preferences? Such questions lie at the heart of the field of European politics and of political science generally. To study them, scholars require measures of mass policy preferences that can be compared across countries and over time. Despite decades of cross-national survey research in Europe, however, measures that meet these standards remain elusive.

The key barrier to cross-national measures is a lack of survey questions repeated consistently across years and European countries. As a consequence, crossnational research on representation and related

Devin Caughey (D), Associate Professor (without Tenure), MIT, Department of Political Science, caughey@mit.edu.

Tom O'Grady, Lecturer, University College London, Department of Political Science, t.o'grady@ucl.ac.uk.

Christopher Warshaw (iD, Assistant Professor, George Washington University, Department of Political Science, warshaw@gwu.edu.

Replication files for this article are available at Caughey, O'Grady, and Warshaw (2018). We wish to thank the editors and three anonymous reviewers for their feedback, and particularly to acknowledge one reviewer whose detailed and extensive comments and questions pushed us to make major improvements to the paper. We are grateful to Elissa Berwick and Clara Vandeweerdt for their help extending the DGIRT model, and to James Dunham for his work on the dgo package. We also appreciate feedback from participations at the 2015 ECPR General Conference. All mistakes, however, are our own. Replication files are available at the American Political Science Review Dataverse: https://doi.org/ 10.7910/DVN/H9XGEB

Received: February 27, 2017; revised: March 1, 2018; accepted: February 8, 2019; First published online: April 10, 2019. topics in European politics has relied instead on indirect proxies for mass policy preferences. By far the most common of these proxies are, first, the average citizen's self-placement on a left-right scale (Huber 1989; Inglehart and Klingemann 1976) and, second, the left-right location of the median voter as inferred from the ideological scores of party manifestos (De Neve 2011; Kim and Fording 1998). The development of these measures was an understandable response to the limitations of existing data and statistical methods, and many excellent and influential studies of the role of mass ideology in European politics would hardly have been possible without them. With these measures, scholars have examined such central issues as governments' ideological congruence with the mass public (Huber and Powell 1994; Mayne and Hakhverdian 2017; McDonald and Budge 2005; Schmitt and Thomassen 1997), their responsiveness to ideological shifts in popular preferences (Adams et al. 2006, 2004; Ezrow et al.2010), and how these relationships are influenced by electoral rules and institutions (Blais and Bodet 2006; Ferland 2016; Golder and Stramski 2010; Powell 2000, 2009).

But as even many scholars that use them admit, these proxies are not ideal measures of citizens' policy preferences per se. Left-right self-placement can depend greatly on political context, imperiling comparison across countries and time, and like other measures of ideological identification is often driven as much by partisan and symbolic attachments as by "operational" policy preferences (Inglehart and Klingemann 1976; Thorisdottir et al. 2007; see also Ellis and Stimson 2012). For their part, median-voter scores hinge on assumptions about party manifesto scores' comparability across countries and the primacy of left-right ideology in determining voters' partisan choices (Kim and Fording 1998, 76-7), thus begging some of the very questions that we wish to answer. Moreover, both of these proxies presume that ideological variation in Europe takes place along a single left-right dimension, an assumption 
that, however plausible in earlier eras, is called into question by the increasing salience of political conflict over non-economic issues (Inglehart 1990; Kitschelt 1994; Knutsen 1995; Kriesi et al. 2006). There is, in short, a clear need for summary measures of mass ideology that are derived directly from citizens' policy preferences, can be compared across time and countries, and reflect the multidimensional character of European politics.

This article introduces measures of mass ideology in European publics designed to meet this need. Taking advantage of recent advances in ideological scaling methods, we estimate the domain-specific policy conservatism of men and women in three age categories and twenty-seven European countries in each biennium between 1981-82 and 2015-16. Specifically, we estimate an ordinal variant of Caughey and Warshaw's (2015) dynamic group-level item response theory (DGIRT) model on a comprehensive dataset of multi-country public opinion surveys, distinguishing among economic, social/postmaterial, and immigration/nationalism issues. For economic issues, we further distinguish between policy "mood," which captures citizens' preferences for less government activity relative to current policy (Stimson 1991), and "absolute" conservatism, which does not depend explicitly on the policy status quo. Because the DGIRT model estimates conservatism at the level of population groups rather than individuals, it surmounts the problem of sparse and uneven question availability that has until now stymied the creation of timeseries-cross-national (TSCS) measures of policy ideology in Europe. This allows us to paint a rich new portrait of the conservatism of European mass publics across multiple issue domains.

Although most of our findings are consistent with previous survey research on issue-specific attitudes, many diverge sharply from the ideological patterns implied by self-placement or median-voter scores. According to our estimates, the European public has become more economically conservative in absolute terms since the 1980 s, but its economic mood - that is, its conservatism relative to the policy status quo-has shifted leftward. Europeans have also become somewhat less conservative on immigration and much less so on social issues. Cross-sectionally, we find that men have always been substantially more conservative than women on economic issues, but not on immigration or (until recently) social issues. On social and immigration issues, conservatism increases markedly with age. On economics, age differences are more muted, but Europeans older than 60 tend to be less conservative than their younger counterparts.

All four measures exhibit a rich-poor gradient across countries that generally divides countries in Northern Europe from those in the South and East. On social and immigration issues, Northern Europeans are the most progressive and Southern and Eastern Europeans are the most conservative. On economic issues, the gradient is reversed. Most Northern publics are more economically right-wing, especially in terms of mood. By contrast, Southern Europe and most of
Eastern Europe, with the exception of a few wealthier countries, tend to be very left-wing on economics. Across countries, economic mood thus has a strong negative association with social and immigration conservatism (which are positively correlated with each other), whereas absolute economic conservatism covaries with economic mood but is essentially uncorrelated with social and immigration conservatism. These patterns indicate that a single left-right dimension cannot capture cross-national ideological variation in Europe. In line with this, we find that selfplacement and median-voter scores are at best weakly associated with policy conservatism in any domain (as well as with each other).

To demonstrate the validity of our measures of policy conservatism, we show that they have a strong crosssectional correlation with responses to highly ideological survey questions in their respective domains. Our conservatism scores also faithfully reflect longitudinal trends in mass conservatism as estimated by Stimson's (1991) Dyad Ratios algorithm. In addition, we evaluate the relationship between our mass ideological measures and government policies. Cross-sectionally, mass-level social progressivism strongly predicts the strength of countries' gay rights policies, and progressivism on immigration does so on pro-immigrant policies. Moreover, within country, variation in economic mood predicts variation in welfare generosity. Notably, our conservatism scores are more highly correlated with each of these policy outcomes than are self-placement and median-voter scores. We also show that mass economic conservatism predicts voting behavior. Overall, we conclude that the ideological constructs measured by our mass conservatism scores are both substantively important and fundamentally distinct from those measured by self-placement and medianvoter scores.

\section{POLICY IDEOLOGY IN EUROPEAN MASS PUBLICS}

The correspondence between citizens' preferences and government policies lies at the core of normative justifications for democracy, if not its very definition, and is thus a central concern of comparative politics (Dahl 1989; for an empirical review, see Powell 2004). Scholars of European politics, site of many of the world's longeststanding democracies, have accordingly developed a rich literature on the content and structure of mass policy preferences.

Citizens' specific attitudes are typically presumed to be structured along one or more ideological dimensions, rooted in divergent interests and values. The cleavage over the distribution of economic resources has always played a central role in structuring ideological conflict and party competition in Europe. Since the seminal work of Lipset and Rokkan (1967), however, the literature on parties and mass behavior has recognized "the importance of alternative, 'second' dimensions of political conflict" over religion and other cultural issues (Häusermann and Kriesi 2015, 202). These two main 
ideological dimensions, typically labeled economic and cultural, have survived or even been reinforced by the rise of new issues such as environmentalism and gay rights, with their content evolving over time as new issues arise (e.g., Inglehart 1984; Kitschelt 1994). One possible exception to this pattern is the recent emergence of issues of national identity, particularly as related to immigration, which some scholars argue has now become a distinct third dimension of political conflict (Heath et al. 1999; Kitschelt and Rehm 2014; but see Kriesi et al. 2006).

The content and relative importance of these ideological dimensions has varied across time and countries. As Inglehart (1990) argues, the increasing salience of "postmaterialist" concerns has been tied to rising levels of wealth. Younger generations, socialized in more affluent circumstances, have placed greater emphasis on postmaterialist values and have tended to be more leftlibertarian than their forebears (Inglehart 1985; Kriesi 1998, 174-6). Moreover, postmaterialism has emerged at different rates across countries depending on their level of economic development. For this and other reasons, scholars have found substantial ideological variation in issue attitudes across European publics, with much of the cross-national variation falling along north-southeast, rich-poor lines.

On economic issues, the publics of Southern and Eastern European countries have generally been found to be more left-wing than their Northern European counterparts. Bonoli (2000), for example, shows that Southern Europe, along with France, stands out as particularly supportive of government intervention in the economy. Similarly, Papadakis and Bean (1993) and Kenworthy and McCall (2008) find Italians to be more supportive of economic redistribution than Northern European publics. Renwick and Tóka (1998), Lipsmeyer and Nordstrom (2003), and Dallinger (2010) find that, with the possible exception of the Czech Republic, Eastern European countries are more left-wing on government spending and other economic issues than countries in Western Europe. Paradoxically, there is at best mixed evidence that the generosity of welfare states is positively correlated with mass support for economic redistribution, government provision of social benefits, or related issue positions (Jaeger 2006). In particular, Scandinavians, despite enjoying arguably the most generous welfare states in the world, express less support for redistributive policies than Germans, Austrians, and other Central Europeans (Jaeger 2009).

The cross-national patterns uncovered by research on cultural and postmaterial issues tend to be the opposite of the patterns on economic issues. Generally speaking, studies of these issues have found that Northern European countries are the most socially progressive, while Southern and Eastern European countries are the most conservative. On gender issues, for example, a small set of countries have highly egalitarian views: the Scandinavian countries plus the Netherlands. Southern and Eastern European countries are the most traditional, with other countries in the middle (Renwick and Tóka 1998; Sjöberg 2004; Treas and Widmer 2000).
Likewise, studies of support for gay rights find a clear north-south and east-west income gradient across countries. Most European countries saw big rises in support for gay rights over the period we examine, with the Scandinavian countries (excluding Finland) and the Netherlands showing the biggest rises. By contrast, aside from Spain, Southern and Eastern European countries did not see substantial rises in support and remain quite opposed to homosexuality (Akker, Ploeg, and Scheepers 2013; Andersen and Fetner 2008; Pew Research Center 2017). Environmental issues exhibit similar cross-national patterns (Franzen and Vogl 2013; Inglehart 1995).

As noted above, some scholars have advocated treating immigration and related issues of national identity as a distinct ideological dimension. Multination survey research of immigration has been comparatively rare, but what work exists finds cross-country patterns similar to those on social issues. Austria, Greece, Hungary, Poland and Portugal stand out as relatively conservative on immigration, and Sweden, Denmark and Switzerland as relatively progressive (Meuleman, Davidov, and Billiet 2009; Semyonov, Raijman, and Gorodzeisky 2008). While correlated with social/cultural attitudes in cross section, immigration attitudes have not been found to share the social issues' clear liberalizing trend over time. In fact, different crossnational studies have documented a mix of increasing, decreasing, and stable trends in anti-immigration attitudes since the late 1980s (Ceobanu and Escandell 2010, 312-3).

\section{Previous Approaches to Summarizing Mass Ideology}

Despite the wealth of cross-national opinion data that have accumulated over the past several decades, scholars of European politics have faced substantial hurdles to summarizing general ideological trends across time and countries. The problem, notes Dalton $(2010,105)$, is that the "diversity of issues across elections and nations [makes it] difficult to systematically and meaningfully compare" mass ideology across political contexts. To surmount these difficulties with direct survey measures of mass issue attitudes, scholars of European politics have turned to proxy measures intended to summarize mass ideology in ways that are comparable across countries and over time. The two most important are citizens' self-placement on a leftright ideological scale and the ideological location of the median voter as inferred from election results and party manifestos.

\section{Self-Placement on a Left-Right Scale}

Beginning with the European Community's 1973 Eurobarometer survey, a large number of crossnational surveys in Europe have included a question asking respondents to place their political views on a ten-point left-right scale, making it the only question that has been asked regularly and consistently across countries and over time. Since their introduction, 
left-right self-placement scores have been used by numerous works to summarize ideological differences across countries and time (e.g., Huber 1989; Knutsen 1998) and to test substantive theories of democratic politics (Adams et al. 2004; Blais and Bodet 2006; Huber and Powell 1994; Schmitt and Thomassen 1997). From the beginning, however, scholars have expressed skepticism toward "the classic view of the left-right dimension... as a super-issue which summarizes the programmes of opposing groups," arguing instead that citizens' ideological self-placement reflects partisan and other group identities, as well as symbolic associations, at least as much as it does issue preferences (Inglehart and Klingemann 1976, 244; see also Huber 1989; Knutsen 1997). ${ }^{1}$

Self-placement scores have also been criticized for differential item functioning, as the meaning of ideological labels can vary substantially across countries and even across individuals and social groups within the same country (Bauer et al. 2017; Lo, Proksch, and Gschwend 2014; Thorisdottir et al. 2007). ${ }^{2}$ "Thus, to a German blue-collar worker," writes Dalton (2010, 105), "Left may still mean social welfare policies; to a young German college student it may mean environmental protection and issues of multiculturalism." If policy preferences are multidimensional, this last fact is particularly problematic because it implies that an individual's self-placement can depend on which policy issues they associate with those labels. In short, although left-right self-placement is the best single-question indicator of mass ideology, it is far from an ideal summary of citizen's policy preferences. ${ }^{3}$

\section{Inferred Median-Voter Locations}

In response to the perceived inadequacies of selfplacement scores, Kim and Fording (1998) developed an alternative measure of voter ideology: the median voter's inferred position on a left-right scale (see also De Neve 2011). This measure is premised on a spatial model of elections in which the only systematic determinant of vote choice is voters' proximity to parties on a left-right ideological dimension. Under this model, the location of the median voter can be inferred from the distribution of vote share across parties with different ideological positions, which Kim and Fording (1998)

\footnotetext{
${ }^{1}$ Klingemann (1979) found that only a minority of European voters know what sorts of policies are associated with the labels "left" and "right."

${ }^{2}$ Several recent studies have used anchoring vignettes and other methods to address the problem of differential item functioning across contexts (e.g., Bakker et al. 2014; Lo, Proksch, and Gschwend 2014). Unfortunately, the survey questions required to use such techniques have not been regularly included on European surveys and thus cannot be used to create measures that extend back more than a decade or so.

${ }^{3}$ Although survey questions on particular issues are not immune to the effects of partisan and symbolic attachments, ideological identification is likely to be more susceptible to such influences. Abstract concepts such as "left" and "right" are more difficult for ordinary citizens to understand, increasing the likelihood that they will rely on heuristics such as their affect toward the social groups they associate with each label.
}

measure using the Comparative Manifesto Project (CMP) ideological ratings of party platforms (Budge et al. 2001). Assuming that this unidimensional spatial model holds and that the coding of party positions is comparable across countries and over time, medianvoter scores are valid measures of mass policy preferences. Median-voter scores' calculability in years and countries without survey data make them particularly powerful measures, and they have been used by a large number of substantive studies (e.g., Adams and SomerTopcu 2009; Kim, Powell, and Fording 2010; McDonald and Budge 2005; Pontusson and Rueda 2010; Stevenson 2001).

Notwithstanding their usefulness, median-voter scores have been subject to a number of criticisms (for a compelling summary, see Warwick and Zakharova 2012). Some of these criticisms stem from problems with the CMP coding that underlies the median-voter scores (Curini 2010; Mikhaylov, Laver, and Benoit 2012). But even granting the validity of the CMP measure of party positions, the spatial-voting assumptions required to infer the location of the median voter from party vote shares are arguably quite strong because they rule out any systematic influences on vote choice aside from ideology. More to the point, insofar as median-voter scores are used to evaluate mass-elite linkages, these assumptions risk begging the question by presuming what they seek to demonstrate.

Finally, both median-voter and self-placement scores share the assumption that European politics takes place along a single left-right dimension. Whether or not this assumption is reasonable for elite politics (for evidence against, see Warwick 2002), it runs counter to the large literature reviewed earlier that emphasizes the multidimensionality of societal cleavages and mass policy preferences. Given that the issue-specific evidence suggests that many countries are left-wing on some issues but right-wing on others, the inadequacy of the assumption of unidimensionality is particularly glaring if the goal is cross-national comparison.

\section{Inferring Ideology from Issue Preferences}

The limitations of self-placement and median-voter scores are widely recognized, and even works that employ them sometimes admit that a direct surveybased measure of mass policy ideology would be preferable. Several recent reviews have called for more attention to and better measures of (multidimensional) issue preferences in the mass public (Powell 2004, 290-1; Evans 2010, 636-7; Franklin 2010, 654). At present, however, self-placement and medianvoter scores are pretty much the only available options for scholars who require a time-varying, cross-national measure of mass ideology. Stevenson (2001, 623-4), for example, laments that while scholars of US politics have measured mass ideology by "combining information from thousands of different survey questions," in other democracies "the available survey data on the policy opinions of citizens... are not nearly as comprehensive..., rendering similar measurements 
for these countries impossible" and requiring the use of proxy measures instead. The crux of the problem, as Kim and Fording $(1998,75)$ put it, is the lack of "enough identical questions... across enough countries to provide a reasonable basis for a survey-based measure of ideology." Though survey-based timeseries of mass policy ideology have been constructed for single countries (Bartle, Dellepiane-Avellaneda, and Stimson 2011; McGann 2014; Stimson, Thiébaut, and Tiberj 2012), to date there has been no equivalent measure available for TSCS analyses across multiple countries.

In the following sections, we describe a strategy for measuring mass ideology that overcomes the problem of sparse survey data and yields dynamic, crossnational, domain-specific measures of mass policy ideology across European countries. Our approach shares elements in common with both existing methods. Like self-placement scores, our measures are based on self-reported assessments of political preferences. Like the median-voter approach, however, we do not measure mass ideology directly, but rather treat it as a latent trait whose distribution can be inferred from aggregate data on citizens' political preferences. Unlike prior approaches, we do not assume a priori that mass ideology is unidimensional, but rather allow it to differ across issue domains. Generating these measures requires both a great deal of survey data and a measurement model linking the data to latent policy ideology. Below, we describe each of these in turn.

\section{SURVEY DATA AND ISSUE DOMAINS}

We constructed a comprehensive dataset containing all multi-year cross-national surveys conducted in Europe between 1981 and 2016. These include the European Social Survey (ESS), various modules of the International Social Survey Program (ISSP), the European Values Survey (EVS), the Pew Global Attitudes Survey, and some special editions of the Eurobarometer. Almost all Western and Southern European countries and nine countries from the former Eastern Bloc appear in the data, for a total of 27 nations in all. ${ }^{4}$ For most of Western Europe, the dataset begins in 1981 with the first cross-national surveys with usable issue questions, but many countries, including Greece, Cyprus, and most of Eastern Europe, do not appear in the data until the end of the 1980s. Every survey question in the dataset concerns domestic policy issues and was asked with identical wording across multiple years and countries.

In light of the debates over the dimensionality of Europeans' issue preferences, we sorted questions into three substantive domains: economic, social, and immigration. The economic domain captures the classic left-right divide over the size and scope of

\footnotetext{
${ }^{4}$ The dataset omits a few European countries, such as Luxembourg, Malta, Croatia, and Serbia, that have been surveyed too infrequently for reliable inference.
}

government and its role in mitigating inequality. The social domain comprises postmaterial and cultural issues such as gender equality, abortion, gay rights, environmental protection, and libertarianism versus authoritarianism. ${ }^{5}$ The immigration domain encompasses questions related to nationalism and national identity as well as those pertaining to immigration specifically.

Within the economic domain, we further distinguish between questions that ask about policy values or outcomes directly and those that ask about the direction of change relative to current policy. ${ }^{6}$ We refer to questions in the first category as absolute and those in the second as relative. This second category roughly corresponds to James Stimson's concept of public policy mood - the public's desire for the government to "do more or less, spend more or less, and tax more or less" (Stimson 2012, 25). Because relative preferences depend on the policy status quo, two individuals from countries with different policies may well differ in their relative preferences even if they share the same absolute preferences. Lipsmeyer and Nordstrom $(2003,340)$, for example, report that Eastern and Western Europeans do not differ on average in their opinions regarding the scope of state responsibility for the needy, but support for increases in state welfare spending is nevertheless significantly higher in Eastern Europe. In short, there are both conceptual and empirical reasons to measure absolute and relative economic conservatism separately from one another.

We thus created four separate datasets with nonoverlapping question sets: absolute economic, relative economic, social, and immigration. As Table 1 indicates, each dataset contains at least 17 survey questions and half a million unique respondents. The absolute economic and social datasets extend back to 1981 while the relative economic and immigration data begin in 1985 and 1990, respectively. ${ }^{7}$ By estimating our measurement model separately on each dataset, we produce four distinct measures of mass conservatism.

We emphasize that our categorization of questions was based on ex ante substantive judgment and not on statistical criteria for selecting the "correct" number of latent dimensions, making it analogous to

\footnotetext{
${ }^{5}$ Although environmental issues are often considered part of a second, "postmaterial" dimension (Inglehart 1995), not all authors agree (e.g., Kriesi et al. 2006). To check whether their inclusion drives our results, we re-estimated our models without environmental issues in the social scale and found that our results were virtually identical (see Supplementary Information (SI), Section 3). Section 2 of the SI also shows that the environmental items are in fact positively correlated with the other social issues items.

${ }^{6}$ We do not make the same distinction for social and immigration questions because relative questions are much less common in those domains, and none are included in our scales.

${ }^{7}$ As Figures S1 and S2 in the SI show, each question is repeated rarely and unevenly across time, but together the survey data provide coverage of a large majority of country-years since 1981 . The SI also provides full information on the sources, wording, and response scales of each question.
} 
TABLE 1. Summary Statistics

\begin{tabular}{lccr}
\hline \multicolumn{1}{c}{ Dataset } & \# Respondents & \# Questions & Year range \\
\hline Absolute economic & 801,725 & 37 & $1981-2016$ \\
Relative economic & 616,674 & 17 & $1985-2016$ \\
Social & 691,549 & 34 & $1981-2016$ \\
Immigration & 551,425 & 21 & $1990-2016$ \\
\hline
\end{tabular}

confirmatory rather than exploratory factor analysis. As we report in the SI (Figure S7), however, we find that nearly all questions in the same dataset are positively correlated, and there is a clear drop-off in explanatory power between the first principal component and higher-order ones. We therefore consider it reasonable to summarize the variation in each dataset with a single latent trait. We recognize, however, that other scholars might make different choices, and to facilitate this we are making our full code available online, together with instructions for how survey questions could be combined differently to produce estimates for other domains or for different numbers of dimensions.

\section{Illustrative Survey Questions}

To illustrate the patterns in our survey data, Figure 1 plots opinion trends on three survey items in each domain (absolute economic, relative economic, social, and immigration). Results are shown for four countries-Hungary, Italy, Norway, and Great Britainfrom different parts of Europe. As this figure makes clear, ideological differences across countries differ substantially depending on the issue domain.

The top row of Figure 1 plots trends on three questions that tap into absolute economic preferences: whether the government should be responsible for mitigating income inequality, tax the rich at a higher rate than the poor, and be responsible for providing for the unemployed. The relative positioning of the countries differs somewhat depending on the question. Great Britain is usually the most conservative country on all three questions, especially since 2000, whereas Italy and Hungary tend to be further left. Norway, by contrast, is relatively conservative on income inequality and progressive taxation, but the most leftwing on providing for the unemployed. In general, Hungary and Italy drifted leftward between the 1990s and 2000s, whereas Norway and Great Britain remained stable or became more conservative. The overall pattern, however, is that opinions on absolute economic issues have remained fairly consistent over time.

Opinion change tends to be larger on questions concerning change relative to the status quo (second row). This makes sense, since relative preferences are a function both of absolute preferences and of current conditions. For example, the British public's position on whether income differences are too large and taxes on the rich too high (second row, first and second columns) shifted sharply rightward between the early and late 1990s, despite little change in the British public's general opposition to government responsibility for inequality and progressive taxation (top row, first and second columns). Hungary exhibited an even more striking leftward shift on these relative questions between the communist-era 1980s and the 2000s. The influence of the status quo may also explain why Norwegians are consistently leftwing on responsibility for the unemployed (first row, third column) but rightwing on whether to spend more on the unemployed (second row, third column), for even someone who leans left relative to most Europeans might nevertheless regard Norway's unusually expansive welfare state as overly generous.

Cross-national differences on social and immigration questions are almost directly opposite to those on economics. On both non-economic domains, Norwegians are clearly the most progressive of the four publics, especially in recent years. On the other end of the ideological spectrum, Hungarians express by far the greatest conservatism on immigration and (except for abortion) social issues. Unlike the other three domains, social issues exhibit an overall trend toward greater progressivism over time, particularly with regard to homosexuality. On immigration, there is some evidence of countervailing opinion trends across countries. Most strikingly, during the refugee crisis of the 2010s, support for banning immigrants from poor countries jumped in Hungary and Italy but fell sharply in Great Britain and to a lesser extent Norway.

As this analysis illustrates, the idiosyncratic variation on individual survey items and their uneven availability across countries and time can make it difficult to discern common trends. Nevertheless, suggestive patterns do emerge when we analyze questions within domains and compare across them. In the next section, we describe a measurement strategy that enables us to bring these patterns into clearer relief using data on many more questions and countries.

\section{MEASUREMENT MODEL}

Using survey responses to estimate citizens' ideology requires a measurement model that connects the (observed) data to the (unobserved) latent trait. Item response theory (IRT) provides a convenient framework for this task. In an IRT model, subjects' responses are 
FIGURE 1. Opinion Trends on Illustrative Survey Questions for Four Countries
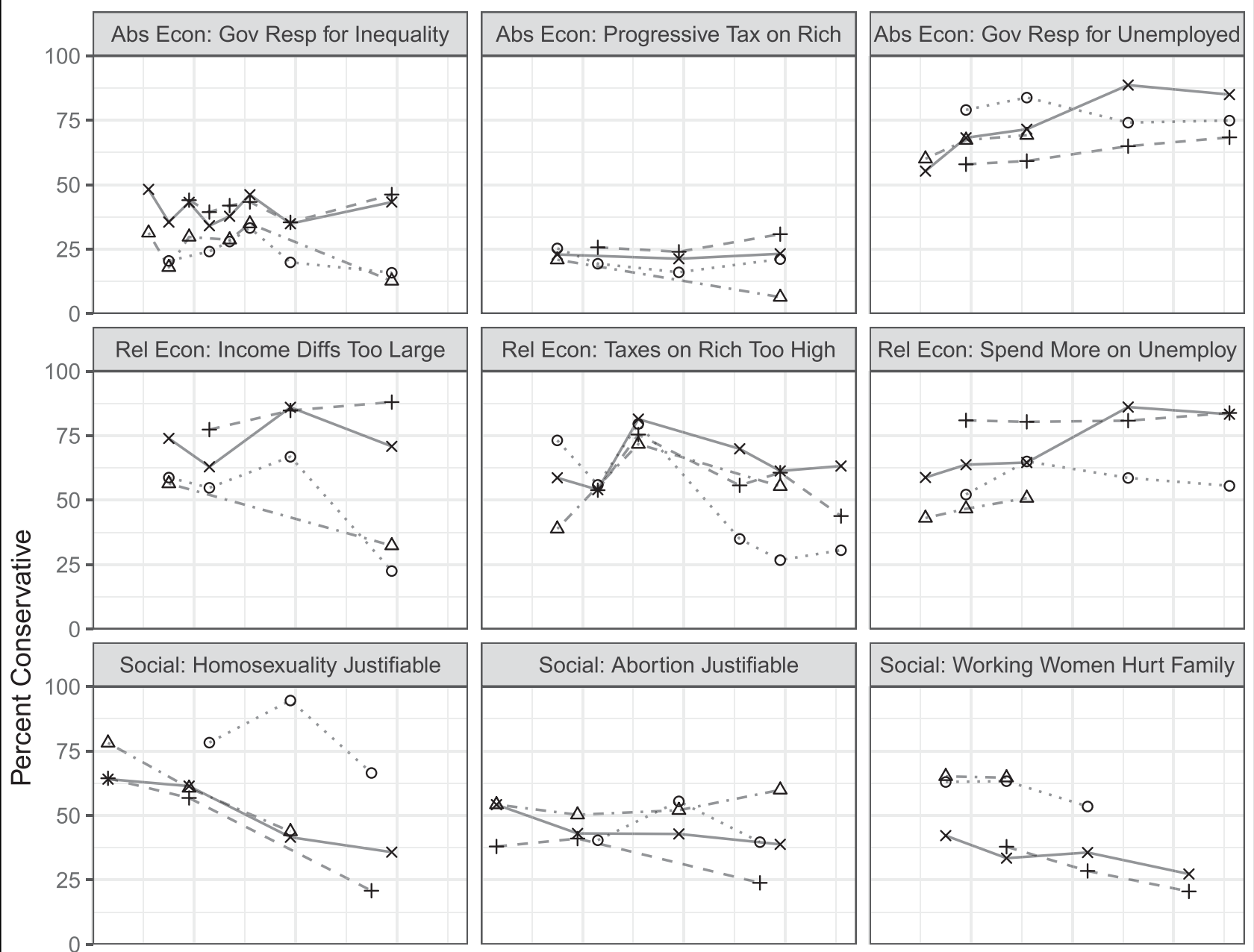

Social: Working Women Hurt Family
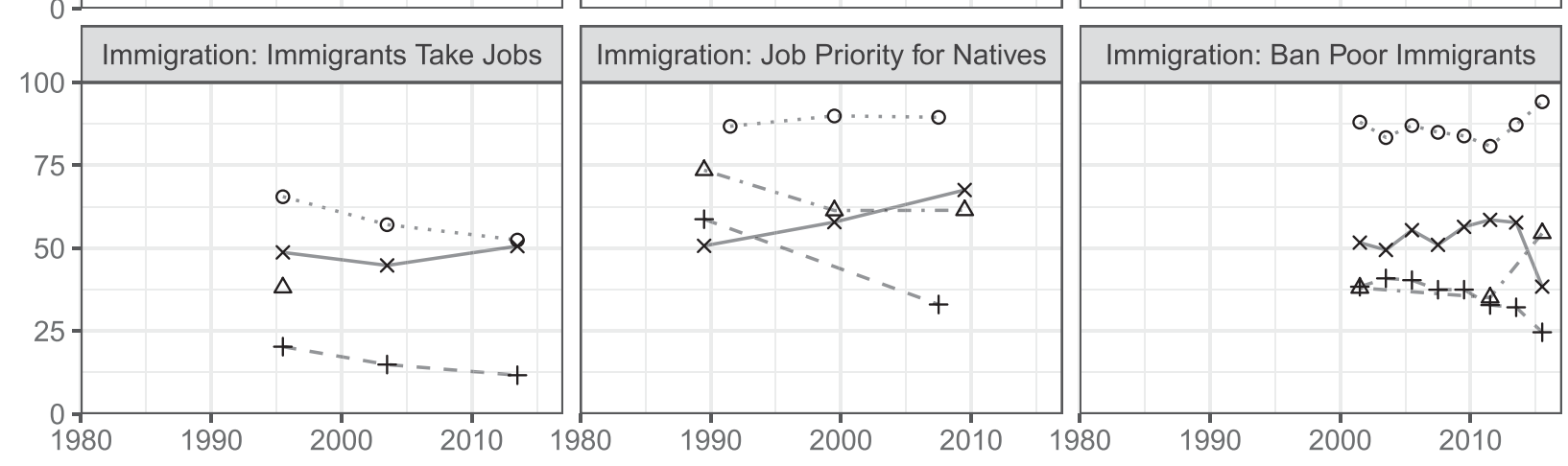

Country $\circ \cdot$ Hungary $\Delta \cdot$ Italy + Norway $\times$ Great Britain

Note: The horizontal axis Indicates the proportion of respondents in the country who were more conservative than average on that question.

jointly determined by their score on the latent trait-in our case, their domain-specific conservatism - and by the characteristics of the particular question. Because most survey items in our dataset offer ordered response options (e.g., strongly agree, agree, neither agree nor disagree, etc.), we employ an ordinal IRT model. In the probit version of this model, subject $i$ 's probability of responding to question $q$ with response option $k \in$ $1 \ldots K_{q}$ is

$\operatorname{Pr}\left(y_{i q}=k \mid \theta_{i}, \beta_{q}, \boldsymbol{\alpha}_{q}\right)=\Phi\left(\beta_{q} \theta_{i}-\alpha_{q, k-1}\right)-\Phi\left(\beta_{q} \theta_{i}-\alpha_{q, k}\right)$,

where $\Phi$ is the normal cumulative distribution function, $\theta_{i}$ is $i$ 's domain-specific conservatism, $\beta_{q}$ is the 
"discrimination" of item $q$ with respect to that trait, and the $K_{q}+1$ thresholds $\boldsymbol{\alpha}_{q}$ are ordered as $-\infty=\alpha_{q, 0}<\alpha_{q, 1}$ $<\ldots<\alpha_{q, K-1}<\alpha_{q, K}=\infty\left(\right.$ Fox 2010, 12-4) ${ }^{8}$

In a typical application, an individual-level IRT model would be used to estimate each respondent's conservatism based on his or her responses to multiple issue questions in a given domain (e.g., Treier and Hillygus 2009). Unfortunately, because European surveys conducted in different countries and time periods have included different survey questions, and each respondent usually answers no more than a handful of questions, an individual-level approach is not feasible in the European context. Our solution to this difficulty is to marginalize over the distribution of conservatism across individuals and instead estimate average conservatism in different segments of the public, using a group-level IRT model (Mislevy 1983). Although our main focus in this application is crossnational comparison, we estimate conservatism at a lower level of aggregation, in groups defined by the cross-classification of country, gender, and age categories. In addition to being substantively interesting, these population groups were chosen because they are measured in a standardized way across countries and surveys and because their population proportions are available from census data, which means that national conservatism can be estimated by weighting the group estimates to match their distribution in the population.

The specific model we use is an ordinal variant of the Bayesian dynamic group-level IRT model developed by Caughey and Warshaw (2015). ${ }^{9}$ In an ordinal DGIRT model, the probability that in period $t$ a randomly sampled member $i$ of population group $g$ selects response option $k$ to item $q$ is

$$
\begin{array}{r}
\operatorname{Pr}\left(y_{i q}=k \mid \bar{\theta}_{g[i][i]}, \beta_{q}, \boldsymbol{\alpha}_{q}, \sigma_{\theta}^{2}\right)=\Phi\left(\frac{\beta_{q} \bar{\theta}_{g[i] t[i]}-\alpha_{q, k-1}}{\sqrt{1+\beta_{q}^{2} \sigma_{\theta}^{2}}}\right) \\
-\Phi\left(\frac{\beta_{q} \bar{\theta}_{g[i] t[i]}-\alpha_{q, k}}{\sqrt{1+\beta_{q}^{2} \sigma_{\theta}^{2}}}\right)=\pi_{t g q k},
\end{array}
$$

where $\bar{\theta}_{g t}$ is the average of $\theta_{i}$ in group $g$ at time $t$ and $\sigma_{\theta}^{2}$ is the variance of $\theta_{i}$ within groups. The vector of probabilities $\pi_{t g q}=\left(\pi_{t g q 1}, \ldots, \pi_{t g q K_{q}}\right)$ can then be linked to the data via a multinomial sampling model,

$$
\boldsymbol{s}_{\text {tgq }} \sim \operatorname{Multinomial}\left(\pi_{\text {tgq }}\right),
$$

where $\boldsymbol{s}_{\operatorname{tgq}}=\left(s_{\operatorname{tgq} 1}, \ldots, s_{\operatorname{tgq} K_{q}}\right)$ is the number of respondents in group $g$ who in period $t$ selected category $k$ in response to question $q$.

In each period, the prior distribution for $\bar{\theta}_{g t}$ is given by a local-level transition model, $\bar{\theta}_{g t} \sim N\left(\bar{\theta}_{g, t-1}, \sigma_{\bar{\theta}}^{2}\right)$. In periods when data are sparse (or absent), this transition

\footnotetext{
${ }^{8}$ In the case of $K_{q}=2$ categories (" 0 " and " 1 "), the ordinal model reduces to the conventional binary IRT model: $\operatorname{Pr}\left(y_{i q}=2=\right.$ "1") $=$ $\Phi\left(\beta_{q} \theta_{i}-\alpha_{q, 1}\right)-\Phi\left(\beta_{q} \theta_{i}-\infty\right)=\Phi\left(\beta_{q} \theta_{i}-\alpha_{q}\right)$.

${ }^{9}$ For an alternative implementation of an ordinal DGIRT model, see Vandeweerdt (2018). For other related models, see McGann (2014), Berwick and Caughey (2018), and Claassen (2019).
}

model smooths (or imputes) estimates of $\bar{\theta}_{g t}$ based on the estimates for adjacent years. To identify the polarity of the latent conservatism space, we restrict each $\beta_{q}$ to be positive (and recode the survey data so that higher responses are more conservative). To identify its location and scale, we normalize the $\bar{\theta}_{t g}$ to have zero mean and unit variance across groups and time periods. We sampled from the posterior distribution of this model using the Bayesian programming language Stan (Stan Development Team 2018), as implemented in $\mathrm{R}$ by the dgo package (Dunham, Caughey, and Warshaw 2019). We ran four chains with 2,000 iterations each, with the first half of each chain as warmup, and based inferences on 4,000 samples from the posterior distribution. For further details on the derivation and implementation of the model, see Sections 8 and 9 of the SI.

\section{ESTIMATES OF MASS POLICY CONSERVATISM}

By applying the ordinal DGIRT model to each of our four datasets, we obtained four biennial measures of the average conservatism of men and women aged 16-34, $35-59$, and $60+$ in each European country. ${ }^{10}$ As noted above, our decision to estimate conservatism at the level of gender $\times$ age groups was based on a combination of substantive considerations and data availability. First, ideological differences between sexes and age groups are theoretically and politically important. Second, these demographic variables are measured consistently across surveys, and data on each group's population share are available for all countries and periods from Eurostat (http://ec.europa.eu/eurostat/data/database). The latter data are necessary in order to poststratify the group estimates into estimates of national averages. Other potentially interesting variables, such as party identification or education, were not examined because they either were measured differently across surveys or did not appear in the Eurostat data, precluding poststratification. ${ }^{11}$

We begin by examining ideological trends for men and women and for the three age groups. In line with existing literature (e.g., Iversen and Rosenbluth 2006), we find that on economic issues, European men, especially young men, have consistently displayed greater conservatism than their female counterparts (Figure 2, top panels). ${ }^{12}$ By contrast, on social and

\footnotetext{
${ }^{10}$ Some surveys include 16 and 17 -year-olds, but most begin at 18 .

${ }^{11}$ Future users of our method may be interested directly in groupspecific rather than national averages, in which case population data for poststratification would not be necessary. Our online guide and code allows users to flexibly estimate their own measures of ideology for particular groups, potentially using subsets of surveys, countries, or years where the relevant data are available.

${ }_{12}$ Figure 2 presents averages across countries, without weighting for country population size. The posterior probability that men are more conservative than women is greater than $95 \%$ in every biennium for 16- to 34-year-olds, in every biennium except 1983-84 and 1985-86 for 35- to 59-year-olds, and for every biennium from 1989-90 onward for those aged $60+$. Note that because estimates of men and women are strongly correlated within year, the confidence intervals exaggerate the overlap between the posterior distributions of men and women.
} 


\section{FIGURE 2. Trends in Mass Conservatism by Gender, Age Group, and Issue Domain}
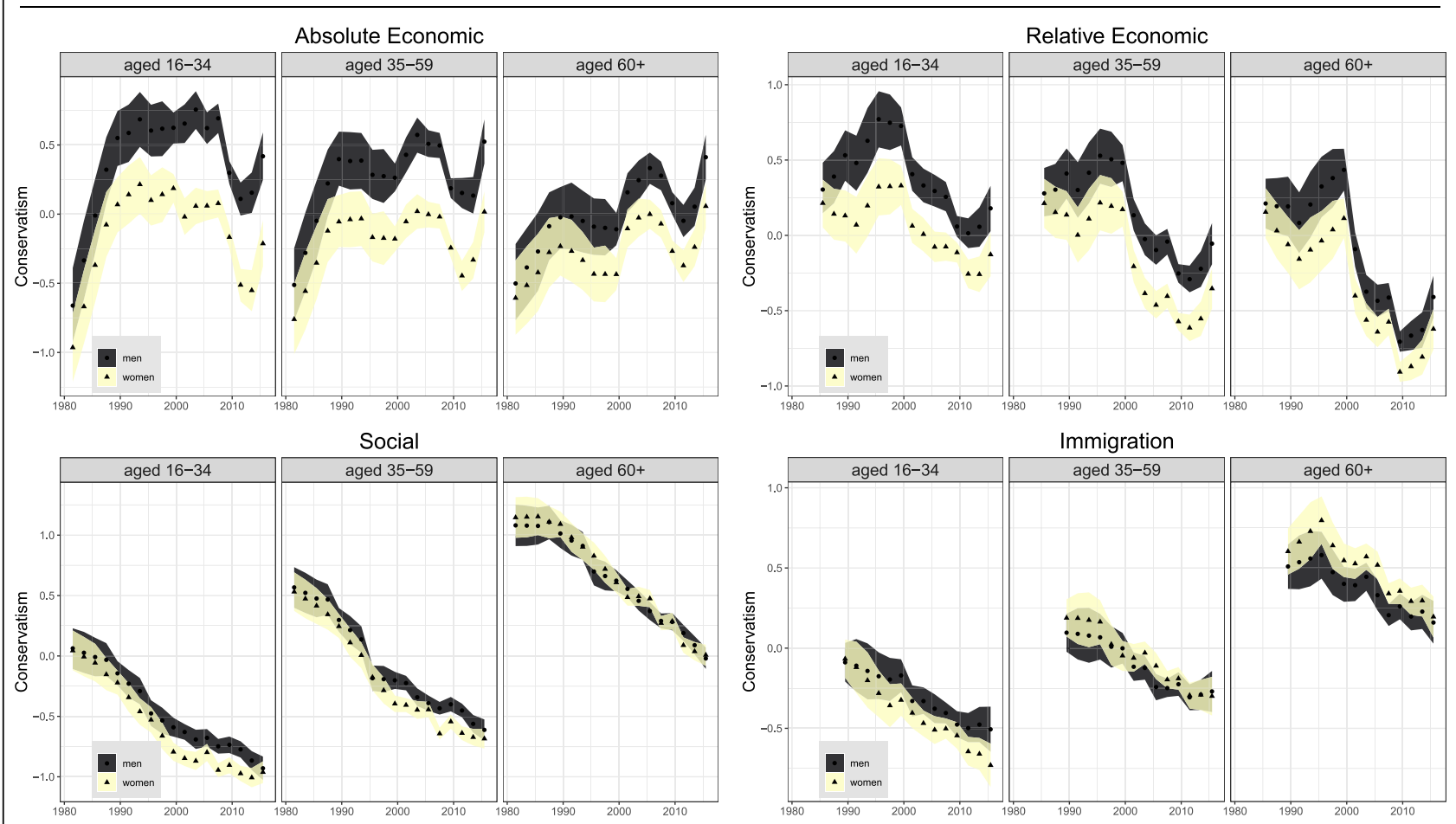

Note: Triangles and lighter color indicate women; circles and darker color indicate men.

immigration issues (bottom panels), men and women are much more similar. There is tentative evidence that a gender gap has developed recently on social issues, as well as hints among young men and women that a similar gap may be emerging on immigration. Overall, however, gender differences are much less pronounced on social and immigration issues than on economics.

Age divides European publics as well, but in different ways across issue domains. ${ }^{13}$ On economic issues, the elderly have been a little more left-wing than the two younger age groups across most of the period, with the young and middle-aged holding very similar positions. For social and postmaterial issues, there is a very clear gradient by age. The youngest people have always been much more socially progressive than the middle-aged, who in turn have always been much more progressive than the oldest. Similarly, on immigration, the elderly are more conservative than the two younger age groups across the whole period.

The four conservatism measures also differ in their trends over time. After increasing substantially in the 1980s, mass economic conservatism plateaued, changing little between 1990 and the early twenty first century. During and immediately after the 2008-09 economic crisis, all groups shifted sharply leftward on

\footnotetext{
13 Our data do not allow us to easily distinguish whether the patterns by age are due to the impact of age itself or to cohort effects, although the patterns could certainly potentially be explained by generational replacement. In any case, our ultimate interest is in using these subgroup results to form national totals. Future research, though, could employ age-period-cohort analysis to address this question.
}

economics. This change proved only temporary, however, as economic conservatism reverted to its precrisis levels by the time our data end in 2016. In contrast, economic mood has trended in a liberal direction since the mid-1990s among all age groups. The divergence between absolute conservatism and policy mood on economic issues could be due to the general retrenchment of the welfare state that occurred across Europe at this time. This retrenchment could have led to thermostatic responsiveness, whereby the public reacts to the decline in the size of government by preferring greater government spending (Soroka and Wlezien 2010).

Social conservatism, on the other hand, declined steadily over the whole thirty-six years of our data, with the most rapid changes occurring in the 1980s and 1990s for the two younger age groups. Due to lack of survey data, we can estimate immigration conservatism only since 1989. We find that it too decreased over the period, albeit less than social conservatism did. Over the past decade, as the immigration crisis in Europe has intensified, this leftward movement appears to have stalled among most age groups.

To estimate mean conservatism in each countrybiennium, we average the estimates for gender-age strata, weighted in proportion to their composition of national populations at each point in time. Figures 3 and 4 plot these estimates over time, separately for each country. Within each panel, countries are ordered according to their average conservatism across years on the respective measure. 
FIGURE 3. Economic Conservatism and Mood within Countries Over Time

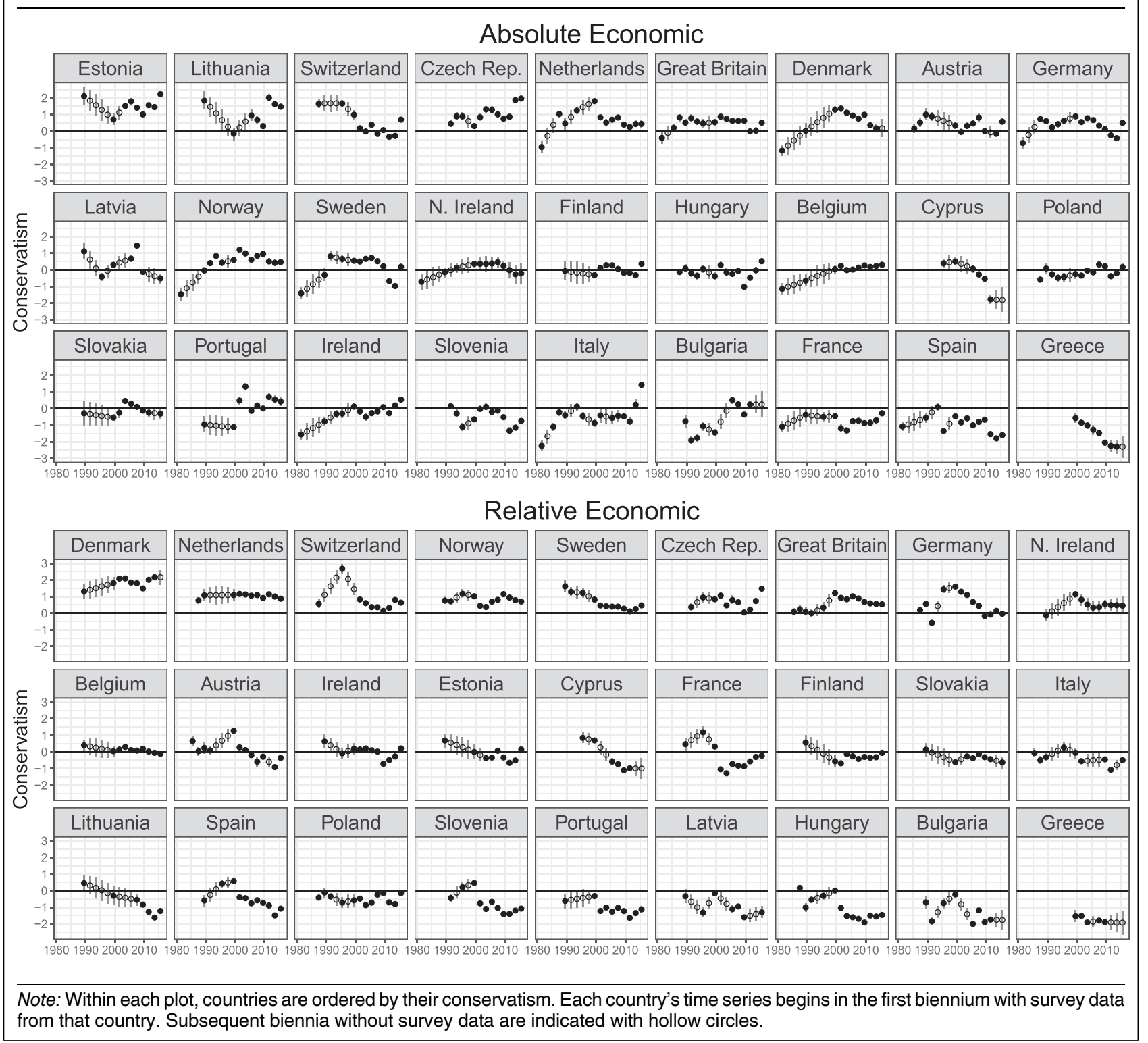

All four figures show a clear north-south ideological divide, but the direction of this cleavage differs across domains. Southern European countries, most notably Greece, tend toward the left-wing end of the economic scales (Figure 3) but are closer to the conservative end of the social and immigration scales (Figure 4). In contrast, Northern countries, such as Denmark and the Netherlands, are the least conservative on social issues and immigration but are more conservative on economics, particularly mood. Meanwhile, on social issues and immigration, Eastern European countries are almost all amongst the most conservative and tend to be similar to Southern European countries. On economic issues, most Eastern European countries also share greater progressivism with their Southern counterparts, although the Czech Republic (with its highest GDP per capita in Eastern Europe), Estonia, and Lithuania are markedly more conservative on absolute economic questions.
Figure 5 plots the cross-national relationships between the four conservatism measures. As the top-left panel shows, social and immigration conservatism have a strongly positive correlation across countries. Moreover, although their trends have differed somewhat over time, there is little sign that immigration conservatism is emerging as a distinct dimension. In 2015-16, for example, the correlation between the two measures $(R=0.78)$ was as high as it has ever been. There is also a robust positive correlation between absolute and relative conservatism on economic issues (top-right). There is, however, a distinct cluster of Eastern European nations whose relative conservatism is much lower than their absolute conservatism would suggest, as well as a few Northern countries (most notably Denmark) whose relative conservatism is anomalously high. Again, the differences between the two economic measures probably reflect the different economic policies in place in the two sets of countries. 


\section{FIGURE 4. Social and Immigration Conservatism within Countries Over Time}

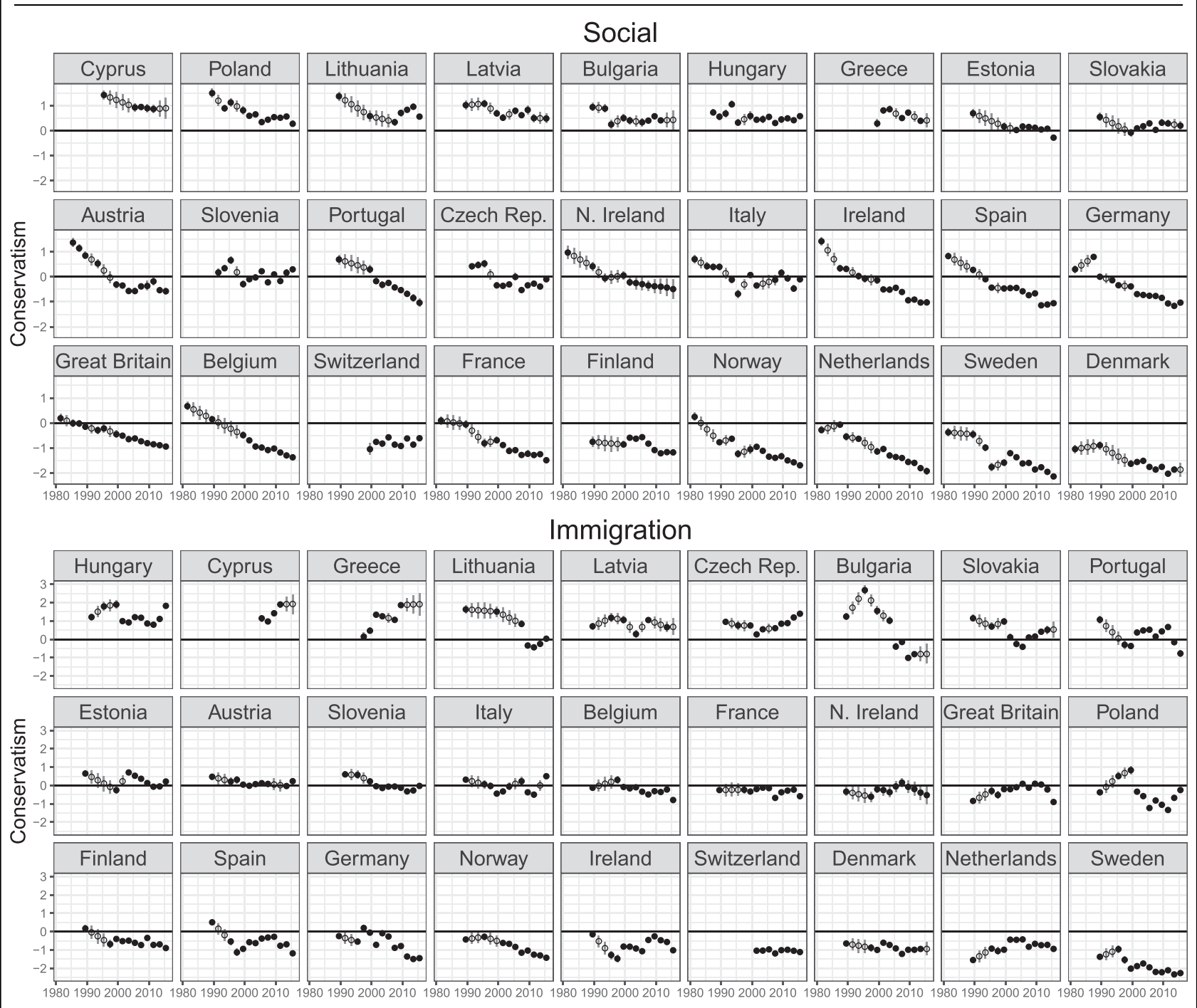

Note: Within each plot, countries are ordered by their conservatism. Each country's time series begins in the first biennium with survey data from that country. Subsequent biennia without survey data are indicated with hollow circles.

Although conservatism is highly correlated within the economic and non-economic domains, this is not true across the domains. As the middle panels show, absolute economic conservatism is essentially unrelated to social and immigration conservatism. Even more strikingly, relative economic conservatism has a strong negative association with both social and immigration conservatism. These negative correlations imply that it is not meaningful to say that certain European publics are conservative across the board. Rather, in contemporary Europe, countries that are conservative on relative economic issues are nearly all fairly progressive on social and immigration issues, and countries that have leftwing economic mood tend to be right-wing on social and immigration issues (compare Malka, Lelkes, and Soto 2017). These patterns thus provide empirical justification for measuring conservatism separately by domain.

\section{VALIDATION}

We provide evidence for the validity of our measures of mass policy conservatism with two kinds of validation: convergent and construct (Adcock and Collier 2001). The purpose of convergent validation is to show that a new measure is empirically associated with alternative measures of the same concept. We do this by comparing our conservatism estimates with responses to individual survey questions and with alternative longitudinal measures of mass conservatism. We then turn to construct validation, the goal of which is to demonstrate the empirical association between a new measure of a given concept and an existing measure of another (distinct) concept believed to be causally related to the concept of interest. We do this by evaluating the relationships between mass conservatism and government policies in the same domain. Overall, we find abundant evidence 
FIGURE 5. Cross-Country Correlations Between Ideological Measures
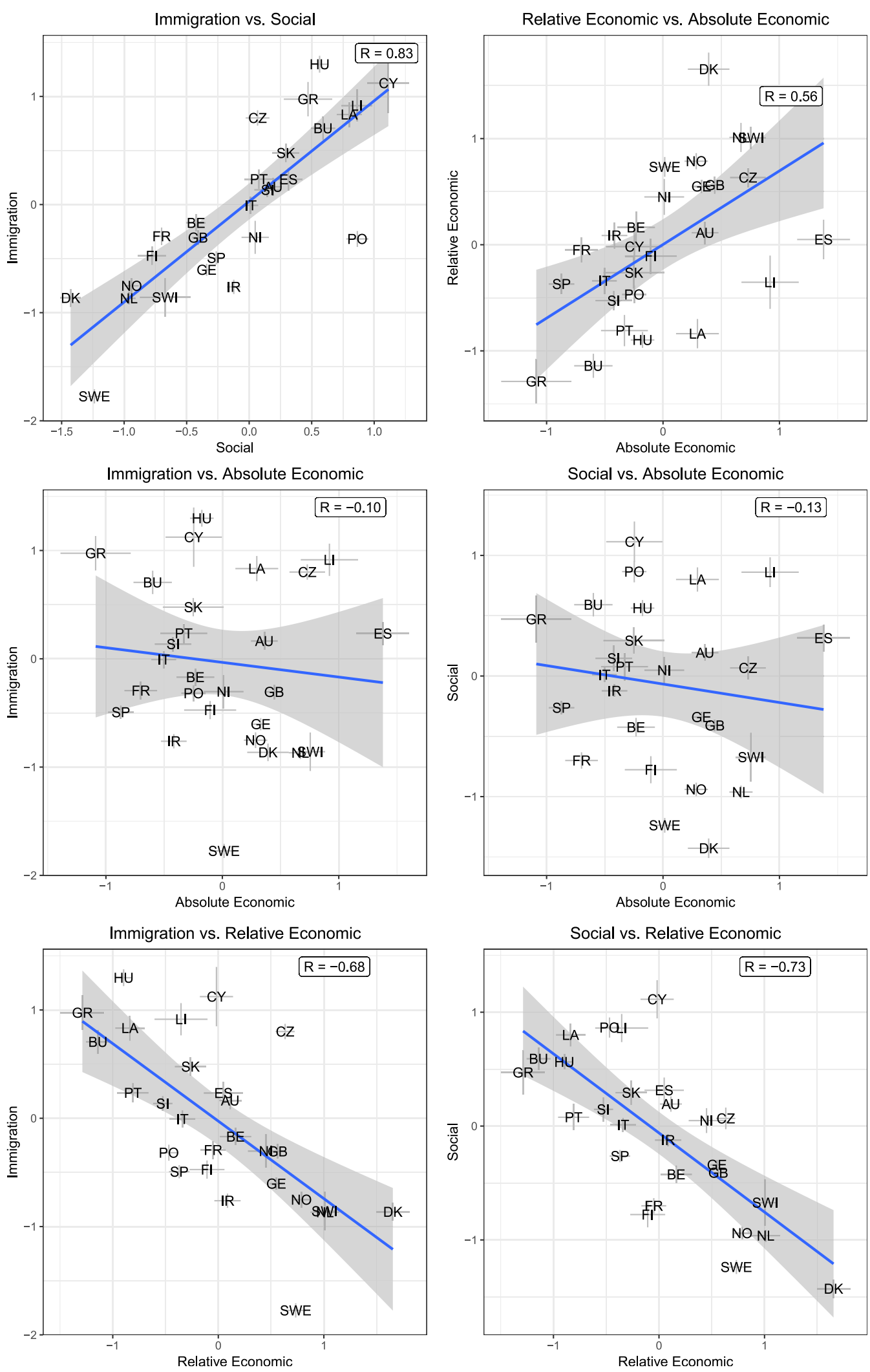

Note: Abbreviations indicate countries' average domain-specific conservatism across all biennia. Gray crosses indicate $95 \%$ credible intervals. 


\section{FIGURE 6. Correlations Between Domain-Specific Conservatism and Individual Issue Questions}
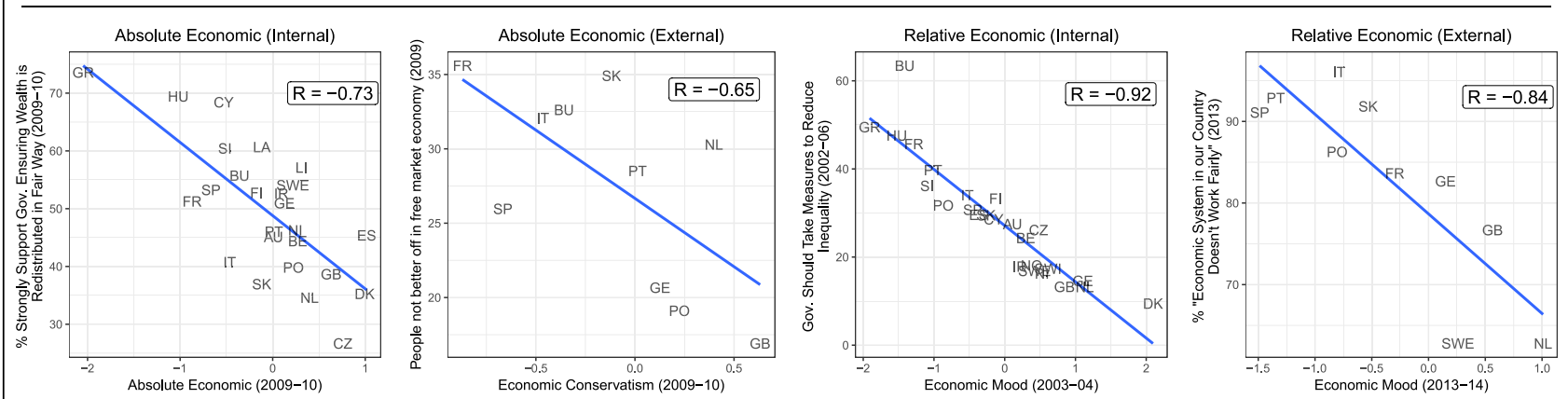

Social (Internal)

Social (External)
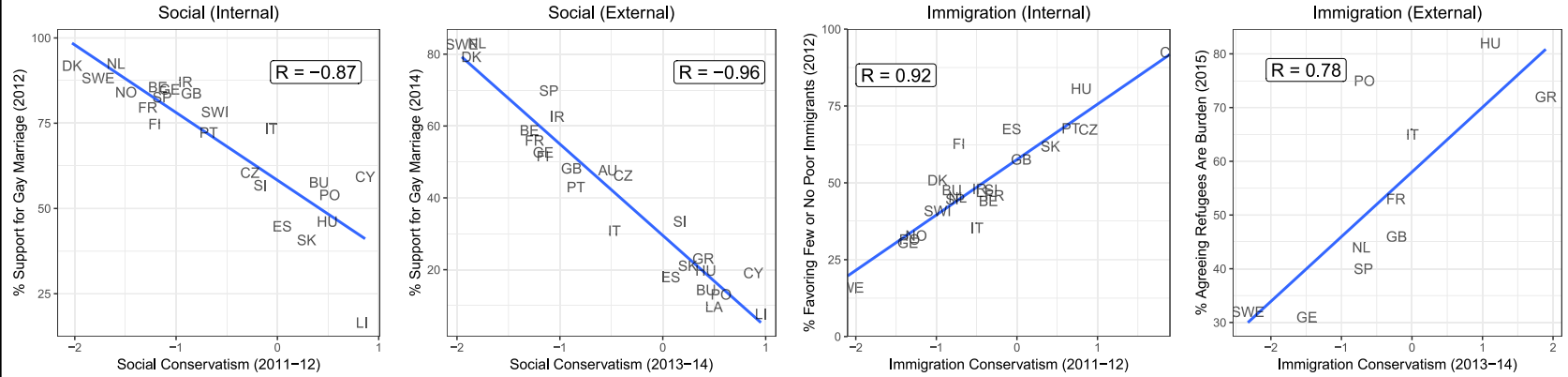

Note: The first and third columns validate the scale against "internal" issue questions included in the data used to estimate the corresponding conservatism scores, whereas the second and fourth columns validate against "external" questions not included in the original data.

that our measures are valid summaries of mass policy preferences in a given domain.

\section{Convergent Validation: Comparison with Survey Measures}

We begin with convergent validation, demonstrating that our measures are strongly correlated with alternative indicators of domain-specific policy preferences. Specifically, we compare our conservatism estimates with responses to highly ideological survey questions in each domain. Figure 6 shows the correlation of our estimates on each domain with one "internal" issue question that is included in the data used to estimate our conservatism scores and one "external" issue question that does not contribute to our estimates. ${ }^{14}$ All of these comparisons show a strong correlation between our ideology estimates and specific issue questions on each domain (see SI, Section 10 for more details).

To complement the cross-sectional comparisons above, we also evaluate the over-time dynamics in our conservatism scores. We do so by using Stimson's (1991) Dyad Ratios algorithm to estimate aggregate trends in domain-specific conservatism and comparing the results with our estimates of average conservatism at each point in time. Since we apply both methods to the same set of data, the primary purpose of this comparison is to show that our results are not driven by the particular model

\footnotetext{
${ }^{14}$ The "external" questions were in all cases not included in our scales because they were asked in only a single year. In certain cases, such as the European Election Study, it may be possible to incorporate the question in future if is repeated across waves.
}

that we use. ${ }^{15}$ The Dyad Ratios algorithm is similar to the DGIRT model in that its goal is to summarize broad ideological patterns across many issue-specific questions. The most important difference between the two methods is that Dyad Ratios leverages only longitudinal variation, whereas the DGIRT model accounts for cross-sectional variation as well. Even though this distinction leads the methods to give items different implicit weights, the two sets of estimates are quite similar. As Figure 7 shows, standardized versions of the two time series generally track each other and are robustly correlated, especially on social and relative economic conservatism. This congruence between the two series provides reassurance that our model faithfully represents longitudinal as well as cross-sectional variation in mass conservatism.

\section{Construct Validation: Policy Representation and Voting}

We now evaluate the relationships between our estimates, and voting and policy outcomes. Assuming that government policies are indeed influenced by mass policy preferences (see Powell 2004, 282-91) and that mass ideology predicts voting behavior, evidence for these theoretical relationships should provide construct validation for our measures. Considering one policy area each for social issues, immigration, and economic mood,

\footnotetext{
${ }^{15}$ We focus this comparison on Western Europe since the large amount of missing data in Eastern European countries limits the time period that Stimson's mood algorithm can be applied for these countries.
} 


\section{FIGURE 7. Comparing Our Domain-Specific IRT Estimates of Mass Conservatism in Western Europe (Averaged Across Countries in Each Biennium) with Analogous Estimates Calculated Using Stimson's Dyad Ratios Algorithm}
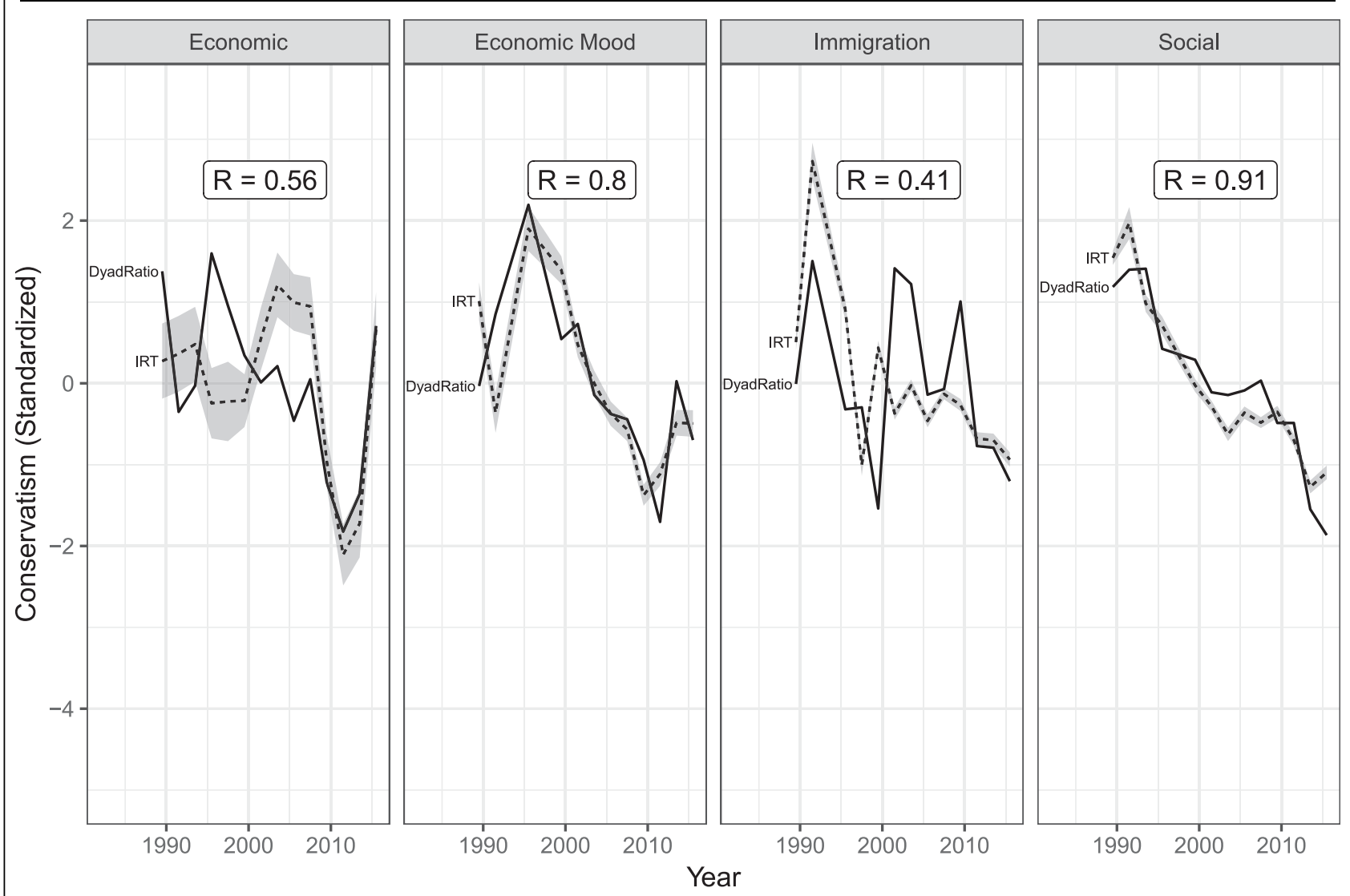

Note: Both models use the same data. All series have been standardized to have zero mean and unit variance within country, and are coded so that higher scores are conservative.

we find that domain-specific ideology not only predicts government policies but also does so better than the two most commonly used measures of mass ideology in the literature to date: left-right self-placement and medianvoter positions. We first report cross-sectional analyses of the social and immigration domains and then describe a panel analysis of economic policy. ${ }^{16}$ Finally, we show that absolute economic conservatism is correlated crosssectionally with voting in European Parliament elections, although here our measure performs about as well as left-right placement.

\section{Social Conservatism and Gay Rights Policy}

First, we examine policy responsiveness on gay rights issues using the European Region of the International Lesbian, Gay, Bisexual, Trans and Intersex Association's "Rainbow Map" of the liberalism of countries' gay rights policies. This index is based on over 50 gay rights policies

\footnotetext{
${ }^{16}$ We focus on cross-sectional analyses of the social and immigration domain due to the lack of panel data on policy outcomes there. In contrast, on economic policy there are good time-series data as well a broad array of obvious confounders for cross-sectional comparisons, which is why for that domain we conduct panel analyses.
}

on topics such as same-sex marriage, non-discrimination laws, and family rights. As the left panel of Figure 8 shows, across countries there is a strong negative association between mass conservatism and the expansiveness of gay rights policies $(r=-0.80)$. In other words, countries where the public has more progressive social views have more progressive policies. As the right panel shows, this is also true of countries where citizens are more likely to place themselves on the "left", but the correlation is about half as strong $(r=-0.46)$ and not statistically significant. ${ }^{17}$ This suggests that gay rights policies are more responsive to domain-specific mass conservatism than to general ideological identification. ${ }^{18}$

\section{Immigration Conservatism and Migrant Integration}

We next conduct an analogous analysis of immigration policy. To capture ideological variation in countries'

\footnotetext{
${ }^{17}$ Data for left-right self-placement come from all Eurobarometer surveys containing the question over the period. Our country-level measure for each period is the weighted average of all individual responses in that period, as in past studies.

${ }^{18}$ We do not compare policy to median-voter scores because our data end in 2004, and even in years before then are often missing in many countries.
} 


\section{FIGURE 8. Cross-Sectional Responsiveness of Gay Rights Policies to Mass Social Conservatism (Left Panel) and Average Self-Placement on the Left-Right Scale (Right Panel)}
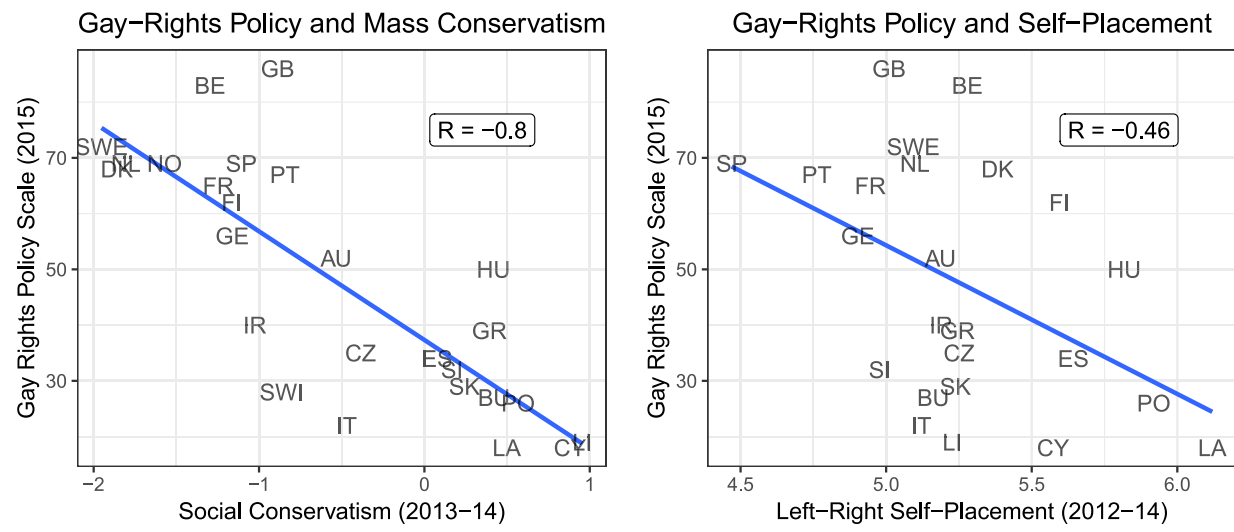

FIGURE 9. Cross-Sectional Responsiveness of Migrant Integration Policies to Mass Immigration Conservatism (Left Panel) and Average Self-Placement on the Left-Right Scale (Right Panel)
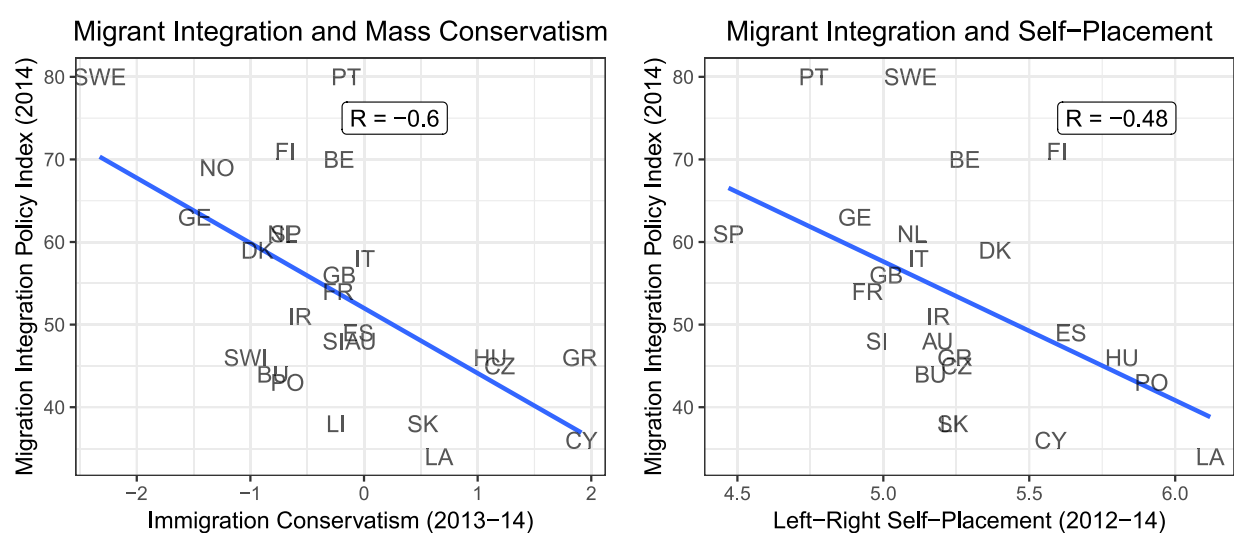

immigration policy we use the Migrant Integration Policy Index (MIPEX), which measures policies to integrate migrants in all EU Member States as well as many other countries around the world. The MIPEX is based on 167 policies related to labor market mobility for migrants, anti-discrimination laws, and many other areas related to migration. As Figure 9 shows, the correlation between government policy and mass conservatism is again stronger than its correlation with left-right self-placement ( $r=-0.60$ versus $r=-0.48)$. Thus, like gay rights, policies designed to integrate migrants into society appear to respond to citizens' immigration-specific conservatism in the receiving country.

\section{Economic Mood and Wage Replacement Rates}

Our next piece of construct validation analyzes the overtime relationship between the generosity of welfare policies and publics' economic mood, taking advantage of the greater availability of time series data on economic policies. We regress policy on opinion while controlling for country- and biennium-specific intercepts, thus ruling out persistent country-specific factors (as well as continent-wide trends) as confounders to the opinion-policy relationship. ${ }^{19}$ The specific policy indicator we analyze is the gross replacement rate-the percent of wages replaced by benefits when a worker loses their job-in each biennium. ${ }^{20}$ A score of $100 \%$ on this metric implies an extremely generous welfare system that replaces all lost income, and a score of $0 \%$ a very stingy one.

Figure 10 summarizes the results of two sets of analysis. ${ }^{21}$ For each measure, we conducted two sets of analysis. The first consisted of two-way fixed-effects

\footnotetext{
${ }^{19}$ We account for within-country dependence by using the wild cluster bootstrap (Esarey and Menger 2018) to calculate confidence intervals. ${ }^{20}$ These data were obtained from the OECD. From our twenty-seven countries, data are not available for Cyprus, Northern Ireland and all Eastern European countries except the Czech Republic, Hungary, Poland, and Slovakia, so we exclude the eight missing countries from this analysis. In addition, data on Italy are available only through 2005-06 and data on the Czech Republic, Hungary, Poland, and Slovakia begin only in 2001 .

${ }^{21}$ Table S1 in the SI presents these regression results in tabular form.
} 


\section{FIGURE 10. Point Estimates and Confidence Intervals from Two-Way Fixed-Effects Regressions of Welfare Replacement Rate on Left-Right Self-Placement Score (Top Row), Median-Voter Location (Middle Row) and Our Estimated Measure of Economic Mood (Bottom Row)}

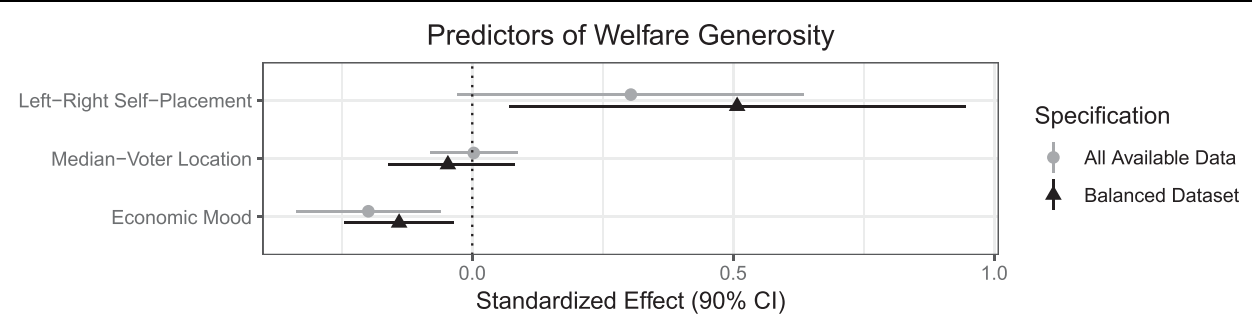

Note: All variables are coded so that higher values are more conservative. The unit of analysis is the country-biennium. The effects have been standardized by rescaling all variables to have unit variance across the observations used in the estimation. Confidence intervals are calculated using the wild bootstrap, clustered by country. The available sample size differs for each measure. In each case, the lighter gray measure uses all available data for the item, and the darker measure shows results from a balanced dataset of only complete observations for all three items.

regression for each of the three measures in turn, containing all possible observations. The sample sizes and coverage differ across these regressions, mainly because median-voter scores are often missing and are only available up to 2004 , forcing us to drop almost $70 \%$ of country-biennia for that measure. ${ }^{22}$ The second analysis also consisted of three regressions, this time with a dataset consisting only of complete observations, so that the samples were identical in each case. The figure shows the coefficients on each of the ideology variables: the predicted response of welfare generosity to a one-unit increase in conservatism (for all three ideology measures, more positive numbers imply greater conservatism).

Regardless of the specification, our measure of mass economic mood exhibits negative covariation with the wage replacement rate, as should be expected (bottom panel of Figure 10): When the public moves to the right in relative economic terms, demanding less spending, welfare spending becomes less generous. The location of the median-voter, on the other hand, has a withincountry relationship with the replacement rate that is close to zero (middle panel). Finally, contrary to what would be expected if policy responded to ideological identification, an increase in the proportion of citizens' placing themselves on the right is positively associated with welfare generosity (top panel). In short, the only variable whose covariance with economic policies is consistent with responsiveness to citizens' preferences is our measure of economic mood. It should be noted that this finding contrasts with the cross-sectional patterns across countries, where the highestspending countries are often the most supportive of spending cuts. Only when we add country-specific intercepts to control for these stable cross-sectional differences is the positive covariation between

\footnotetext{
${ }^{22}$ The median voter positions come from an update to the original Kim-Fording dataset produced by De Neve (2011). They are available only in country-biennia when elections were held, and even in this updated data set, they are also only available up to 2004 .
}

conservative economic policymaking and public mood revealed.

\section{Economic Conservatism and European Parliament Elections}

Our final piece of construct validation conducts an analogous analysis of absolute economic conservatism. To capture ideological variation in election outcomes, we use data on the share of left-wing parties in the 2013 EU Parliamentary Elections. As Figure 11 shows, the correlation between EU Parliamentary Elections and mass conservatism is moderately strong, though slightly less so than the correlation between election results and self-placement. Thus, EU elections appear to respond to citizens' economic-specific conservatism, but there is no evidence of a superior relationship to self-placement.

\section{COMPARISON TO PROXIES FOR MASS POLICY PREFERENCES}

We now turn to a direct comparison between our estimates and left-right self-placement and medianvoter positions. As noted above, self-placement scores capture citizens' identification with different ideological labels, and median-voter positions are inferred from election results under assumptions of spatial voting. Moreover, both existing measures presume that mass policy preferences in Europe vary along a single left-right dimension. It is therefore reasonable to suspect that self-placement and median-voter scores may have weak relationships with at least one and possibly all four of our measures.

This is in fact what we find. The first thing to note is that despite purportedly measuring the same concept, left-right self-placement and median-voter scores are almost uncorrelated with each other $(R=0.14$ across countries; $R=-0.02$ across country-biennia). Both Danes and Norwegians, for example, tend to place themselves almost identically toward the center-right end of the ideological scale. But according to median-voter scores, the median Danish voter is centrist whereas the 


\section{FIGURE 11. Cross-Sectional Responsiveness of EU Elections to Mass Economic Conservatism (Left Panel) and Average Self-Placement on the Left-Right Scale (Right Panel)}
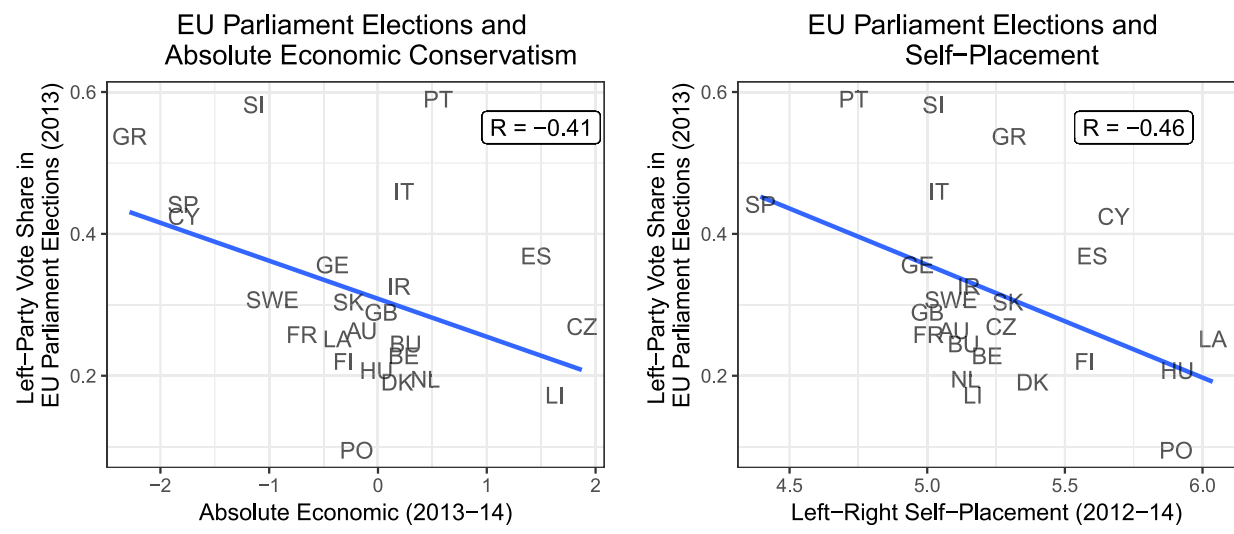

\section{FIGURE 12. Correlations Between Self-Placement Scores, Median-Voter Locations, and Our Measures} of Domain-Specific Conservatism
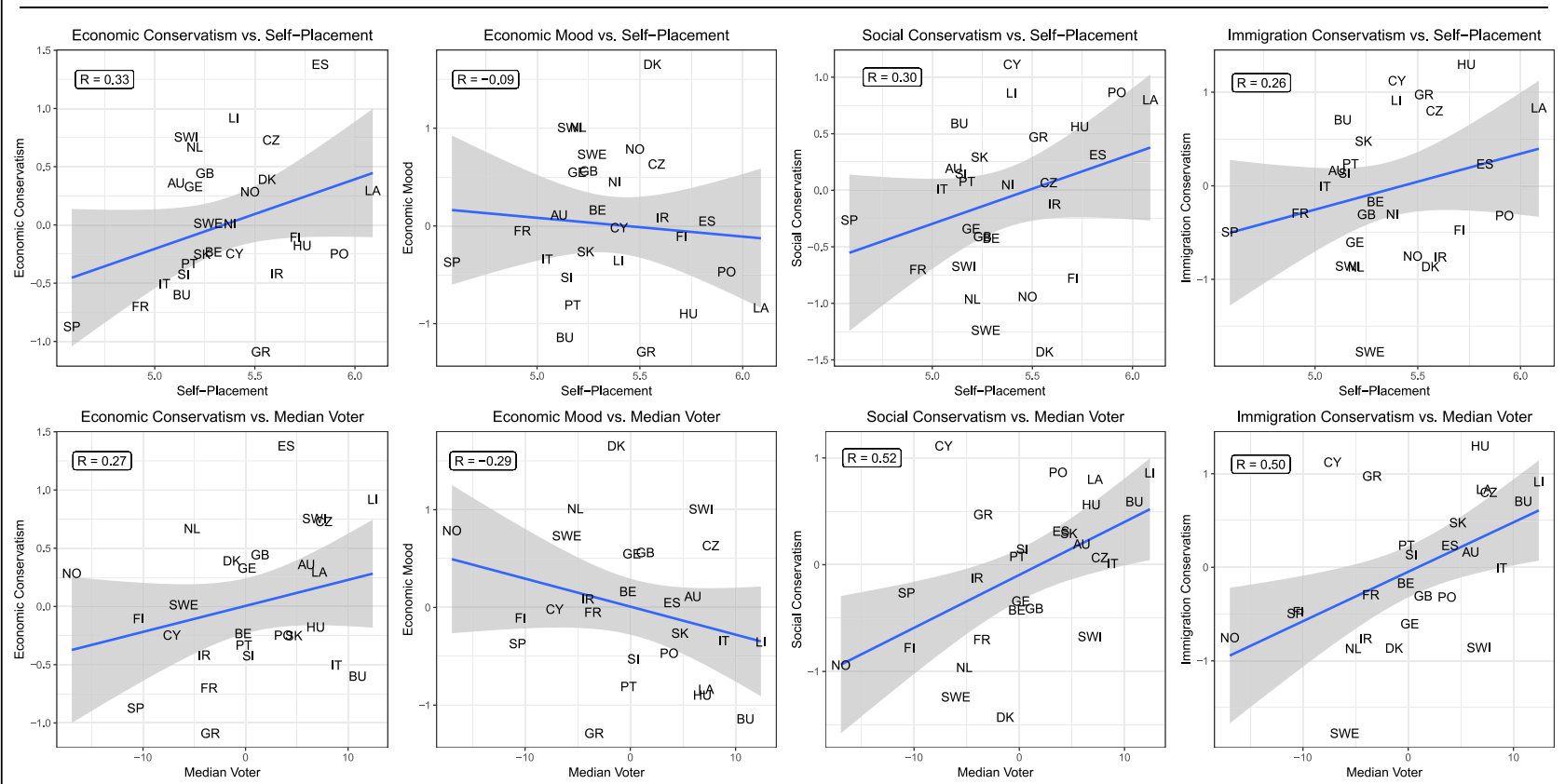

Note: Each observation is an average for the relevant country across years. The data end in 2004 for the median voter scores and in 2016 for all other plots.

median Norwegian is extremely left-wing. Similarly, the median voter in both Italy and Bulgaria is estimated to be very right-wing, but citizens in both countries place themselves on the left. It appears likely that citizens in different countries are thinking of different ideological dimensions when describing their ideological positions. Danes and Norwegians, for example, may be thinking of economic issues given that most place themselves toward the right. On the other hand, Greeks and Poles also consistently rate themselves as relatively right-wing, which is in line with their stance on social issues and immigration but not on economics.
Figure 12 summarizes the bivariate relationships between self-placement and median-voter scores and our four domain-specific measures. With the exception of relative economic conservatism (economic mood), all of our measures display a positive cross-national correlation with both self-placement and median voter scores. The correlations are generally modest, however, only topping 0.5 in the case of median-voter scores' correlations with immigration and social conservatism. Regressions using our domain-specific measures to explain the two proxies for ideology reveal the same patterns. Although there are modest positive correlations in most cases, the predictive power of our survey- 
based measures is not great: collectively, they explain only $17 \%$ of the variation in self-placement scores and $13 \%$ of the variation in median voter scores in a multivariate regression. ${ }^{23}$

The temporal patterns in the measures contrast with each other as well. As others (e.g., Knutsen 1998; Medina 2015) have observed, over the past decades there has been little aggregate movement toward the left or right in citizens' ideological self-placement. Median-voter scores, by contrast, are in many countries much more variable over time. As Warwick and Zakharova $(2012,174)$ note, some of this variation is implausibly large. Portugal, for example, is estimated to have gone from having one of the most right-wing electorates in Europe to one of the most left-wing in just twelve years (1987 to 1999). Similarly, between 1998 and 2001 Denmark moved about a standard deviation to the right on the median-voter scale. Neither country's survey-based ideological positions changed over those periods in so dramatic a fashion. A likely explanation is that these large shifts are caused by changes in vote shares that may not reflect voters moving closer to certain parties ideologically, but rather the effect of economic conditions, shifts in party positions, or other valence considerations.

In summary, self-placement and median-voter scores, in addition to being essentially uncorrelated with each other, are at best weakly related to survey-derived summaries of the public's domain-specific conservatism. This suggests that the two existing measures are not especially good proxies for mass policy preferences and in fact measure distinct concepts.

\section{CONCLUSION}

We have described the first dynamic, cross-national summaries of mass conservatism derived from Europeans' issue preferences. The measures cover 27 countries, 36 years, and four issue domains: absolute economic, relative economic, social, and immigration. We have validated our measures against individual issue questions, time series of domain-specific policy mood, and policies themselves, finding robust evidence of their validity.

Our measures indicate that since the 1980s, European publics have moved markedly leftward on social issues and modestly so on immigration. Europeans' support for conservative revisions to existing economic policies declined as well, even as their absolute economic conservatism slightly increased. On economics, men have consistently taken more conservative positions than women, but only recently has any sign of an analogous gender gap emerged on social and immigration issues. Social and immigration conservatism increases strongly with age, but on economics, age matters little for absolute conservatism and if anything is

\footnotetext{
${ }^{23}$ These inferences are from a least-squares regression with, social, and immigration, and both measures of economic conservatism as regressors and the country-biennium as the unit of the analysis. The full regression results are shown in Table S2 in the Supplementary material.
}

associated with lower values of relative conservatism. All four measures exhibit a clear regional divide across countries. Compared to Southern and Eastern Europeans, Northern Europeans tend to be more progressive on social and immigration issues but more conservative on economics.

The negative relationship between economic conservatism and social and immigration conservatism indicates that cross-national variation in European mass ideology cannot be captured with a single left-right dimension, at least as those labels are commonly understood. Thus, in many contexts our domain-specific measures of policy conservatism may be preferable to unidimensional measures such as self-placement and median-voter. While the latter remain valuable as measures of ideological identification and electoral preferences, applied scholars should consider whether they capture the construct of theoretical interest.

Given the central place that citizens' policy preferences play in normative and positive theories of politics, the scope of potential applications of our measures is vast. In addition to facilitating descriptive inferences about ideological patterns in the mass public, they can also be used to examine governments' responsiveness to citizens' preferences, as we have shown. These analyses could of course be extended to examine the institutional and contextual moderators of policy representation. Additional topics include the role that mass policy preferences play in electoral outcomes and these preferences' responsiveness to shifting economic and social conditions. We hope and expect that other researchers use our estimates to explore these and other important questions. To facilitate this, we have made our estimates available to the public and will continue to update them as more survey data are released.

\section{SUPPLEMENTARY MATERIAL}

To view supplementary material for this article, please visit https://doi.org/10.1017/S0003055419000157.

Replication materials can be found on Dataverse at: https://doi.org/10.7910/DVN/H9XGEB.

\section{REFERENCES}

Adams, James, Michael Clark, Lawrence Ezrow, and Garrett Glasgow. 2004. "Understanding Change and Stability in Party Ideologies: Do Parties Respond to Public Opinion or to Past Election Results?" British Journal of Political Science 34 (4): 589-610.

Adams, James, Michael Clark, Lawrence Ezrow, and Garrett Glasgow. 2006. "Are Niche Parties Fundamentally Different from Mainstream Parties? The Causes and Consequences of Western European Parties' Policy Shifts, 1976-1998.” American Journal of Political Science 50 (3): 513-29.

Adams, James, and Zeynep Somer-Topcu. 2009. "Policy Adjustment by Parties in Response to Rival Parties' Policy Shifts: Spatial Theory and the Dynamics of Party Competition in Twenty-Five Post-War Democracies." British Journal of Political Science 39 (4): 825-23.

Adcock, Robert, and David Collier. 2001. "Measurement Validity: A Shared Standard for Qualitative and Quantitative Research." American Political Science Review 95 (3): 529-46.

Akker, Hanneke van den, Rozemarijn van der Ploeg, and Peer Scheepers. 2013. "Disapproval of Homosexuality: Comparative 
Research on Individual and National Determinants of Disapproval of Homosexuality in 20 European Countries." International Journal of Public Opinion Research 25 (1): 64-86.

Andersen, Robert, and Tina Fetner. 2008. "Economic Inequality and Intolerance: Attitudes toward Homosexuality in 35 Democracies." American Journal of Political Science 52 (4): 942-58.

Bakker, Ryan, Seth Jolly, Jonathan Polk, and Keith Poole. 2014. "The European Common Space: Extending the Use of Anchoring Vignettes." The Journal of Politics 76 (4): 1089-101.

Bartle, John, Sebastian Dellepiane-Avellaneda, and James Stimson. 2011. "The Moving Centre: Preferences for Government Activity in Britain, 1950-2005." British Journal of Political Science 41 (2): 259-85.

Bauer, Paul C., Pablo Barbera, Kathrin Ackermann, and Aaron Venetz. 2017. "Is the Left-Right Scale a Valid Measure of Ideology? Individual-Level Variation in Associations with 'Left' and 'Right' and Left-Right Self-Placement." Political Behavior 39 (3): 553-83.

Berwick, Elissa, and Devin Caughey. 2018. "Multidimensional Latent Preferences from Sparse Survey Data: A Group-Level Dynamic IRT Model for Spanish Regions." Poster presented at the summer meeting of the Society for Political Methodolgy, Brigham Young University, Provo, UT.

Blais, André, and Marc André Bodet. 2006. "Does Proportional Representation Foster Closer Congruence between Citizens and Policy Makers?" Comparative Political Studies 39 (10): 1243-62.

Bonoli, Giuliano. 2000. "Public Attitudes to Social Protection and Political Economy Traditions in Western Europe." European Societies 2 (4): 431-52.

Budge, Ian, Hans-Dieter Klingemann, Andrea Volkens, Judith Bara, and Eric Tanenbaum. 2001. Mapping Policy Preferences: Estimates for Parties, Electors and Governments 1945-1998. Oxford, UK: Oxford University Press.

Caughey, Devin, Tom O'Grady, and Christopher Warshaw. 2018. Replication Data for: Policy Ideology in European Mass Publics, 1981-2016. https://doi.org/10.7910/DVN/H9XGEB.

Caughey, Devin, and Christopher Warshaw. 2015. "Dynamic Estimation of Latent Opinion Using a Hierarchical Group-Level IRT Model." Political Analysis 23 (1): 197-211.

Ceobanu, Alin M., and Xavier Escandell. 2010. "Comparative Analyses of Public Attitudes toward Immigrants and Immigration Using Multinational Survey Data: A Review of Theories and Research." Annual Review of Sociology 36 (1): 309-28.

Claassen, Christopher. 2019. "Estimating Smooth Country-Year Panels of Public Opinion." Political Analysis 27 (1): 1-20.

Curini, Luigi. 2010. "Experts' Political Preferences and Their Impact on Ideological Bias." Party Politics 16 (3): 299-321.

Dahl, Robert A. 1989. Democracy and Its Critics. New Haven, CT: Yale University Press.

Dallinger, Ursula. 2010. "Public Support for Redistribution: What Explains Cross-National Differences?” Journal of European Social Policy 20 (4): 333-49.

Dalton, Russell J. 2010. "Left-Right Orientations, Context, and Voting Choices." In Citizens, Context, and Choice, eds. Russell J. Dalton and Christopher J. Anderson. New York: Oxford University Press, 103-22.

De Neve, Jan-Emmanuel. 2011. "The Median Voter Data Set: Voter Preferences across 50 Democracies." Electoral Studies 30 (4): $865-71$.

Dunham, James, Devin Caughey, and Christopher Warshaw. 2019. dgo: Dynamic Estimation of Group-Level Opinion. R package version 0.3.00. https://jdunham.io/dgo/.

Ellis, Christopher, and James A. Stimson. 2012. Ideology in America. New York: Cambridge University Press.

Esarey, Justin, and Andrew Menger. 2018. "Practical and Effective Approaches to Dealing with Clustered Data." Political Science Research and Methods: 1-19. Pre-published online 19 January 2018. https://doi.org/10.1017/psrm.2017.42.

Evans, Geoffrey. 2010. "Models, Measures and Mechanisms: An Agenda for Progress in Cleavage Research." West European Politics 33 (3): 634-47.

Ezrow, Lawrence, Catherine De Vries, Marco Steenbergen, and Erica Edwards. 2010. "Mean Voter Representation and Partisan Constituency Representation: Do Parties Respond to the Mean Voter Position or to Their Supporters?" Party Politics 17 (3): 275-301.
Ferland, Benjamin. 2016. "Revisiting the Ideological Congruence Controversy." European Journal of Political Research 55 (2): $358-73$.

Fox, Jean-Paul. 2010. Bayesian Item Response Modeling: Theory and Applications. New York: Springer.

Franklin, Mark N. 2010. "Cleavage Research: A Critical Appraisal." West European Politics 33 (3): 648-58.

Franzen, Axel, and Dominikus Vogl. 2013. "Two Decades of Measuring Environmental Attitudes: A Comparative Analysis of 33 Countries." Global Environmental Change 23 (5): 1001-8.

Golder, Matt, and Jacek Stramski. 2010. "Ideological Congruence and Electoral Institutions.” American Journal of Political Science 54 (1): 90-106.

Häusermann, Silja, and Hanspeter Kriesi. 2015. "What Do Voters Want? Dimensions and Configurations in Individual-Level Preferences and Party Choice." In The Politics of Advanced Capitalism. Chap. 8, eds. Pablo Beramendi, Silja Häusermann, Herbert Kitschelt, and Hanspeter Kriesi. New York: Cambridge University Press, 202-30.

Heath, Anthony, Bridget Taylor, Lindsay Brook, and Alison Park. 1999. "British National Sentiment." British Journal of Political Science 29 (1): 155-75.

Huber, John D. 1989. "Values and Partisanship in Left-Right Orientations: Measuring Ideology." European Journal of Political Research 17 (5): 599-621.

Huber, John D., and G. Bingham Powell. 1994. "Congruence between Citizens and Policymakers in Two Visions of Liberal Democracy." World Politics 46 (3): 291-326.

Inglehart, Ronald. 1984. "The Changing Structure of Political Cleavages in Western Society." In Electoral Change in Advanced Industrial Societies: Realignment or Dealignment, eds. Russell Dalton, Scott C. Flanagan, and Paul Allen Beck. Princeton, NJ: Princeton University Press, 25-69.

Inglehart, Ronald. 1985. "Aggregate Stability and Individual-Level Flux in Mass Belief Systems: The Level of Analysis Paradox." American Political Science Review 79 (1): 97-116.

Inglehart, Ronald. 1990. Culture Shift in Advanced Industrial Society. New York: Princeton University Press.

Inglehart, Ronald. 1995. "Public Support for Environmental Protection: Objective Problems and Subjective Values in 43 Societies." PS: Political Science and Politics 28 (1): 57-72.

Inglehart, Ronald, and Hans-Dieter Klingemann. 1976. "Party Identification, Ideological Preference and the Left-Right Dimension Amongst Western Mass Publics." In Party Identification and beyond: Representations of Voting and Party Competition. Chap. 13, eds. Ian Budge, Ivor Crewe, and Dennis Fairlie. London, UK: Wiley, 243-73.

Iversen, Torben, and Frances Rosenbluth. 2006. "The Political Economy of Gender: Explaining Cross-National Variation in the Gender Division of Labor and the Gender Voting Gap." American Journal of Political Science 50 (1): 1-19.

Jaeger, Mads Meier 2006. "Welfare Regimes and Attitudes towards Redistribution: The Regime Hypothesis Revisited." European Sociological Review 22 (2): 157-70.

Jaeger, M. M. 2009. "United but Divided: Welfare Regimes and the Level and Variance in Public Support for Redistribution." European Sociological Review 25 (6): 723-37.

Kenworthy, Lane, and Leslie McCall. 2008. "Inequality, Public Opinion and Redistribution." Socio-Economic Review 6 (1): 35-68.

Kim, HeeMin, and Richard C. Fording. 1998. "Voter Ideology in Western Democracies, 1946-1989." European Journal of Political Research 33 (1): 73-97.

Kim, HeeMin, G. Bingham Powell Jr., and Richard C. Fording. 2010. "Electoral Systems, Party Systems and Ideological Representation: An Analysis of Distortion in Western Democracies." Comparative Politics 42 (2): 167-85.

Kitschelt, Herbert. 1994. The Transformation of European Social Democracy. New York: Cambridge University Press.

Kitschelt, Herbert, and Philipp Rehm. 2014. "Occupations as a Site of Political Preference Formation.” Comparative Political Studies 47 (12): 1670-706.

Klingemann, Hans-Dieter. 1979. "Measuring Ideological Conceptualizations." In Political Action: Mass Participation in Western Democracies, eds. Samuel Barnes and Max Kaase. London: Sage Publications, 215-54. 
Knutsen, Oddbjorn. 1995. "Value Orientations, Political Conflicts and Left-Right Identification: A Comparative Study." European Journal of Political Research 28 (1): 63-93.

Knutsen, Oddbjorn. 1997. "The Partisan and the Value-Based Component of Left-Right Self-Placement: A Comparative Study." International Political Science Review 18 (2): 191-225.

Knutsen, Oddbjorn. 1998. "Europeans Move towards the Center: A Comparative Longitudinal Study of Left-Right Self-Placement in Western Europe." International Journal of Public Opinion Research 10 (4): 292-316.

Kriesi, Hanspeter. 1998. "The Transformation of Cleavage Politics." European Journal of Political Research 33: 165-85.

Kriesi, Hanspeter, Edgar Grande, Romain Lachat, Martin Dolezal, Simon Bornschier, and Timotheos Frey. 2006. "Globalization and the Transformation of the National Political Space: Six European Countries Compared." European Journal of Political Research 45 (6): 921-56.

Lipset, Seymour Martin, and Stein Rokkan. 1967. "Cleavage Structures, Party Systems, and Voter Alignments: An Introduction.” In Party Systems and Voter Alignments Cross-National Perspectives. Chap. 1, eds. Seymour Martin Lipset and Stein Rokkan. New York: Free Press, 1-65.

Lipsmeyer, Christine, and Timothy Nordstrom. 2003. "East versus West: Comparing Political Attitudes and Welfare Preferences across European Societies." Journal of European Public Policy 10 (3): 339-64.

Lo, James, Sven-Oliver Proksch, and Thomas Gschwend. 2014. "A Common Left-Right Scale for Voters and Parties in Europe." Political Analysis 22 (2): 205-23.

Malka, Ariel, Yphtach Lelkes, and Christopher J. Soto. 2017. "Are Cultural and Economic Conservatism Positively Correlated? A Large-Scale Cross-National Test." British Journal of Political Science: 1-25. Pre-published 30 May 2017. doi: 10.1017/ S0007123417000072.

Mayne, Quinton, and Armen Hakhverdian. 2017. "Ideological Congruence and Citizen Satisfaction: Evidence from 25 Advanced Democracies." Comparative Political Studies 50 (6): 822-49.

McDonald, Michael D., and Ian Budge. 2005. Elections, Parties, Democracy: Conferring the Median Mandate. Oxford, UK: Oxford University Press.

McGann, Anthony J. 2014. "Estimating the Political Center from Aggregate Data: An Item Response Theory Alternative to the Dyad Ratios Algorithm.” Political Analysis 22 (1): 115-29.

Medina, Lucía. 2015. "Partisan Supply and Voters' Positioning on the Left-Right Scale in Europe." Party Politics 21 (5): 775-90.

Meuleman, Bart, Eldad Davidov, and Jaak Billiet. 2009. "Changing Attitudes toward Immigration in Europe: A Dynamic Group Conflict Theory Approach." Social Science Research 38: 825-50.

Mikhaylov, Slava, Michael Laver, and Kenneth R. Benoit. 2012. "Coder Reliability and Misclassification in the Human Coding of Party Manifestos." Political Analysis 20 (1): 78-91.

Mislevy, Robert J. 1983. "Item Response Models for Grouped Data." Journal of Educational Statistics 8 (4): 271-88.

Papadakis, Elim, and Clive Bean. 1993. "Popular Support for the Welfare State: A Comparison between Institutional Regimes." Journal of Public Policy 13 (3): 227-54.

Pew Research Center. 2017. Religious Belief and National Belonging in Central and Eastern Europe. Available at: http:// www.pewforum.org/2017/05/10/religious-belief-and-nationalbelonging-in-central-and-eastern-europe/.
Pontusson, Jonas, and David Rueda. 2010. "The Politics of Inequality: Voter Mobilization and Left Parties in Advanced Industrial States." Comparative Political Studies 43 (6): 675-705.

Powell, G. Bingham. 2000. Elections as Instruments of Democracy: Majoritarian and Proportional Visions. New Haven, CT: Yale University Press.

Powell, G. Bingham. 2004. "Political Representation in Comparative Politics." Annual Review of Political Science 7: 273-96.

Powell, G. Bingham. 2009. "The Ideological Congruence Controversy: The Impact of Alternative Measures, Data and Time Periods on the Effects of Electoral Rules." Comparative Political Studies 42: 1475-97.

Renwick, Alan, and Gábor Tóka. 1998. "East Meets West?” In British and European - Social Attitudes: The 15th Report: How Britain Differs, eds. Roger Jowell, John Curtice, Alison Park, Lindsay Brook, Katarina Thomson, and Caroline Bryson. Aldershot, UK: Ashgate, 149-71.

Schmitt, Hermann, and Jacques Thomassen. 1997. "Policy Representation." European Journal of Political Research 32 (2): 165-84.

Semyonov, Moshe, Rebeca Raijman, and Anastasia Gorodzeisky. 2008. "Foreigners' Impact on European Societies: Public Views and Perceptions in a Cross-National Comparative Perspective." International Journal of Comparative Sociology 49 (1): 5-29.

Sjöberg, Ola. 2004. "The Role of Family Policy Institutions in Explaining Gender-Role Attitudes: A Comparative Multilevel Analysis of Thirteen Industrialized Countries." Journal of European Social Policy 14 (2): 107-23.

Soroka, Stuart N., and Christopher Wlezien. 2010. Degrees of Democracy: Politics, Public Opinion, and Policy. New York: Cambridge University Press.

Stan Development Team. 2018. RStan: The R Interface to Stan. $\mathrm{R}$ package version 2.17.3. http://mc-stan.org/.

Stevenson, Randolph T. 2001. "The Economy and Policy Mood: A Fundamental Dynamic of Democratic Politics?" American Journal of Political Science 45 (3): 620-33.

Stimson, James A. 1991. Public Opinion in America: Moods, Cycles and Swings. Boulder, CO: Westview Press.

Stimson, James A. 2012. "On the Meaning \& Measurement of Mood." Daedalus 141 (4): 23-34.

Stimson, James A., Cyrille Thiébaut, and Vincent Tiberj. 2012. "The Evolution of Policy Attitudes in France." European Union Politics 13 (2): 293-316.

Thorisdottir, Hulda, John T. Jost, Ido Liviatan, and Patrick E. Shrout. 2007. "Psychological Needs and Values Underlying Left-Right Political Orientation: Cross-National Evidence from Eastern and Western Europe." Public Opinion Quarterly 71 (2): 175-203.

Treas, Judith, and Eric D. Widmer. 2000. "Married Women's Employment over the Life Course: Attitudes in Cross-National Perspective." Social Forces 78 (4): 1409-36.

Treier, S., and D. S. Hillygus. 2009. "The Nature of Political Ideology in the Contemporary Electorate." Public Opinion Quarterly 73 (4): 679-703.

Vandeweerdt, Clara. 2018. "Worldwide Trends in Climate Change Opinions." Unpublished manuscript, January 19.

Warwick, Paul V. 2002. "Toward a Common Dimensionality in West European Policy Spaces.” Party Politics 8 (1): 101-22.

Warwick, Paul, and Maria Zakharova. 2012. "Measuring the Median: The Risks of Inferring Beliefs from Votes." British Journal of Political Science 43 (1): 157-75. 